\title{
1 On the sensitivity of low temperature combustion to spark assist near flame limit conditions
}

2 Laura K. Manofsky Olesky ${ }^{\mathrm{a}}$

3 manofsky@umich.edu

4 Robert J. Middleton ${ }^{\mathrm{a}}$

$5 \quad$ rjmidd@umich.edu

6 George A. Lavoie ${ }^{\mathrm{a}}$

7 glavoie@umich.edu

$8 \quad$ Margaret S. Wooldridge ${ }^{\mathrm{b}}$

9 mswool@umich.edu

10 Jason B. Martz

11 jmartz@umich.edu

$12{ }^{a}$ W. E. Lay Automotive Laboratory, University of Michigan, 1231 Beal Avenue, Ann Arbor, MI, United 13 States, 48109

$14{ }^{\mathrm{b}}$ George G. Brown Laboratories, University of Michigan, 2350 Hayward Street, Ann Arbor, MI, United 15 States, 48109

16 Corresponding Author: Laura K. Manofsky Olesky

Tel: (734) 647-1409

Fax: (734) 764-4256 
Abstract

Spark assisted compression ignition (SACI) is a practical mode for controlling the heat release 35 rate of low temperature combustion (LTC). While flames are key phenomena in the SACI combustion 36 process, they may not always be effective or viable under the mildly stratified and highly dilute low 37 burned gas temperature conditions of LTC. To better understand the limits of flammability or flame 38 effectiveness, this work explores combustion within a single cylinder direct injection engine near the high 39 load limit of the HCCI combustion regime, where spark induced flame propagation has been seen to 40 affect combustion phasing and heat release rate. Flame limiting conditions were identified using 41 progressively more advanced spark timing, up to $120^{\circ}$ before top dead center, for differing levels of air 42 and EGR dilution while holding the chemical energy content of the charge constant. Under air dilute 43 conditions, the measured combustion phasing advanced from $8^{\circ}$ to $0^{\circ}$ after top dead center with spark 44 advance, while almost no effect was seen under EGR dilute conditions. Estimates of the experimental 45 global and local state conditions were made at the time of spark using heat release analysis and a KIVA$463 \mathrm{~V}$ engine model, respectively, and the flammability for each case was evaluated using the Karlovitz 47 criterion. The results show that fuel rich stratification near the spark plug was likely responsible for the observed variations in the SACI flame behavior.

\section{$49 \quad$ Keywords}

50 Homogeneous charge compression ignition (HCCI)

$51 \quad$ Spark assisted compression ignition (SACI)

52 Low temperature combustion (LTC)

53 Flame quenching

$54 \quad$ Flammability

55

56

57 


\section{Introduction}

Spark assisted compression ignition (SACI) has been demonstrated as a method to control the

61 phasing, burn rate, and stability of a primarily auto-igniting fuel/air charge [1,2]. Optical engine studies

62 of SACI suggest the spark event initiates flame propagation within a highly dilute mixture, accelerating

63 the auto-ignition of the surrounding unburned charge via compression heating [3-5]. The spark provides a

64 crucial parameter for control during transient mode switches between homogeneous charge compression

65 ignition (HCCI), SACI, and spark ignited (SI) combustion, which may be necessary to implement low

66 temperature combustion (LTC) in practical engines [6, 7]. Understanding the effectiveness of dilute

67 SACI flames and their ability to control combustion phasing at a given operating condition is critical for

68 avoiding periods of excessive pressure rise rates or instability and misfire.

While experience has shown that gasoline fueled spark ignited engines encounter a lean limit at

70 approximately $30 \%$ dilution by mass [8], it is possible to sustain flames under higher levels of dilution

71 provided the unburned gas temperature $\left(T_{u}\right)$ is in the vicinity of the auto-ignition temperature and the

72 energy content of the charge is sufficiently high [9]. For a given spark timing, as $T_{u}$ increases conditions

73 become more favorable for auto-ignition and flame propagation tends to become an increasingly smaller

74 percentage of the overall heat release [2]. In practical SACI engines, $T_{u}$ and dilution level are controlled

75 by valve timing strategies that retain large quantities of high temperature residual gas, which can range

76 from $30 \%$ to $60 \%$ of the total charge mass, depending on engine load [2].

77 Due to high levels of charge dilution, SACI flames have reduced burned gas temperatures $\left(T_{b}\right)$

78 relative to undilute stoichiometric flames typical of SI engines [9]. Laminar flame simulations have

79 predicted that premixed flames can be sustained under ultra-dilute conditions provided that $T_{b}$ exceeds

$80 \sim 1450$ to $1500 \mathrm{~K}$ [10-13]; otherwise, flame quenching can be induced by processes such as turbulent

81 strain or external heat loss [14-17]. It has been proposed based upon dimensional analysis that when the

82 flame thickness exceeds the smallest scales of the turbulent flow, transport rates within the flame are

83 increased, broadening it to the point where there is a sharp drop in temperature that leads to flame

84 extinction. This limit is known as the Klimov-Williams criterion [18]. However, the existence of such 
behavior has not been directly confirmed; rather, flames have been observed to remain viable even when the flame thickness is many times that of the smallest scale of the turbulent flow, both experimentally and

87 in direct simulation $[16,17,19]$.

Several fundamental experiments have examined turbulent flame quenching. Abdel-Gayed et al. [20] compared schlieren images of turbulent flames from fan stirred bombs over a broad range of turbulent intensities and equivalence ratios for both hydrocarbon and hydrogen fuels to define the regimes of turbulent flame propagation. Flame appearance and quenching were well correlated to the Karlovitz

$92(\mathrm{Ka})$ and Lewis numbers. Roberts et al. [17] used a laminar toroidal vortex to quench laminar premixed methane flames with a fuel-to-air equivalence ratio $(\phi)$ equal to 0.55 . The maximum temperature of the product gases for the unperturbed laminar flames was $1525 \mathrm{~K}$; quenching was observed to occur when the product gas temperatures cooled to $\sim 1300 \mathrm{~K}$. Quenching vortex Karlovitz numbers ( 4.5-14) were similar to the two-dimensional direct numerical simulations of Poinsot et al. [16]. Roberts et al. [17] also

97 found the quenching $K a$ for propane-air flames differed from that of methane-air flames, indicating the importance of detailed chemistry and transport properties to the quenching process. experiments in a single cylinder engine with adjustable compression ratio to understand if flame initiation and/or flame propagation limited lean SI operation. In the experiments, spark timing was advanced earlier into compression and away from maximum brake torque (MBT) timing to define the ignition limit where the onset of misfire occurred. Additionally, the partial burn/flame propagation limit was found by retarding spark timing from MBT until incomplete flame propagation, as determined by the lack of an ionization signal near the cylinder wall, occurred in at least $2-4 \%$ of the cycles. As the mixture was leaned, the two limits converged at the MBT lean misfire limit $(\phi=0.65)$, indicating that both ignition

107 and flame propagation constrain highly dilute operation. Peterson et al. [21] used high-speed fuel 108 fluorescence and particle image velocimetry measurements combined with spark discharge measurements to identify the cause of misfire and partial burn cycles in a stratified spark ignited direct injection engine. The results of the study showed abnormal spark behavior was not the cause of misfire, as all cycles had 
111 sufficient electrical spark energy to ignite the mixture near the spark plug. For the cycles that misfired, it 112 was shown that a flame kernel developed but failed to propagate due to the highly lean/dilute mixtures 113 surrounding the flame kernel. under the highly dilute conditions typical of SACI/LTC. Dai et al. [15] validated a misfire model for SI 116 combustion based on the flame quench correlations reported in the Leeds diagram of Abdel-Gayed et al. 117 [20]. The model was implemented into a cycle simulation, which in turn determined the parameters 118 necessary for the misfire model. With the misfire model, the cycle simulation was capable of predicting 119 corresponding experimental misfire limits (defined when at least 0.5 to $1 \%$ of the total cycles misfired) 120 for two engine designs using a variety of equivalence ratios, exhaust gas recirculation (EGR) rates, spark 121 timings, and speeds and loads. For this definition of misfire, the experimental misfire limit closely 122 matched the quenching limit of the Leeds diagram based on model predictions of turbulent flow and 123 laminar flame characteristics at the time of spark. Dai et al. [15] predicted that this result would likely be 124 applicable to most SI engines.

A variety of diluents can be used with LTC, and it is well known that dilution method impacts the combustion process. Dilution with EGR as opposed to air has been studied extensively in HCCI and SI 127 combustion, including the effects on ignition delay time and laminar flame speed. Dec et al. [22] and 128 Olsson et al. [23] showed that the use of EGR as opposed to air dilution reduced peak rates of heat release 129 and increased combustion duration for HCCI combustion at constant phasing (CA50). Kodavasal et al. 130 [24] used CFD modeling to compare air and EGR dilute HCCI combustion with the same ignition timing, 131 minimal compositional stratification, and similar levels of thermal stratification. The results showed that 132 differences in burn duration between the cases were due to variations in the mixture ratio of specific 133 heats, which affected the work transfer between the earlier and later burning portions of the HCCI charge. Laminar flame simulations by Middleton et al. [13] indicated laminar burning velocities 135 decreased with increased levels of EGR dilution (versus air dilution) due to thermal and chemical effects. 136 Flame speed was shown to be most sensitive to the high temperature chain branching and chain 
terminating reaction rates which were affected by the mixture $\mathrm{O}_{2}$ concentration. These results suggest that EGR dilute mixtures are less likely to be affected by spark assist than air dilute mixtures with the same charge energy content. It was also noted in Olesky et al. [25] that the early rates of heat release 140 consistent with flame propagation were more rapid for air dilute SACI conditions compared with EGR 141 dilute SACI conditions at constant fueling, spark timing, combustion phasing, and dilution level.

The sensitivity of low temperature combustion to spark assist near flame limiting conditions continues to be an area of high uncertainty and little experimental data. In the current study, a novel

144 method is used to quantify the sensitivity of HCCI/SACI operation to spark ignition at $\sim 4$ bar ( $0.4 \mathrm{MPa})$

145 net indicated mean effective pressure $\left(\operatorname{IMEP}_{\mathrm{n}}\right)$, a load condition where flames have been shown to have 146 an influence on the timing and rate of combustion [26, 27]. (At loads less than 3 bar IMEP ${ }_{n}$, almost no 147 spark effect has been seen as the mixture is very dilute [26-28]). The experiments presented here, 148 performed on a single cylinder metal engine with a gasoline direct injection fuel system, studied the 149 effects of air/EGR dilution and spark timing on combustion phasing while holding the chemical energy 150 content of the charge constant. Detailed analysis of the experimental results was performed to understand the processes governing the observed SACI heat release rates and to provide insight into proposed flame 152 limiting behaviors.

\section{2. Experimental apparatus and methods}

\section{$154 \quad 2.1$ Research engine}

Experiments were performed with a single cylinder gasoline direct injection research engine.

156 Key geometric parameters are listed in Table 1, with a complete description of the experimental facility 157 provided in a previous publication [2]. The four valve engine is equipped with a fully flexible valve 158 actuation system, allowing for independent control of valve lift and duration. With this system, a large 159 amount of internal EGR was retained using symmetric negative valve overlap (NVO) in which the early 160 closing of the exhaust valve during the exhaust stroke trapped hot residual gases in the cylinder to initiate combustion in the following cycle. An external EGR loop with a water-cooled heat exchanger allowed 
cooled EGR gases to be introduced to the intake manifold, where electric heaters controlled the

163 temperature of the incoming charge. Gasoline with an anti-knock index (AKI, i.e. the mean of the

164 research and motor octane numbers) of 87 was delivered from a solenoid fuel injector mounted between

165 the two intake valves during the early part of the intake stroke (during NVO) at $330^{\circ}$ before top dead

166 center (bTDC) of combustion. A spark plug with a gap of $0.9 \mathrm{~mm}$ was mounted in the center of the

167 cylinder head. The rated energy delivered from the spark plug coil $(\sim 70 \mathrm{~mJ})$ was held constant

168 throughout the experiment.

\subsection{Data acquisition and combustion analysis}

Cylinder pressure data was sampled at $0.1^{\circ}$ crank angle (CA) resolution for 200 consecutive cycles using a piezoelectric pressure transducer (Kistler 6125A). Pressure dynamics in the intake and exhaust runners were recorded at the same resolution using piezoresistive transducers (Kistler 4007 and 4045, respectively) mounted near the ports. A wideband oxygen sensor (ETAS LA4) in the exhaust manifold was used to determine the fuel-to-air equivalence ratio $(\phi)$, while exhaust constituents $\left(\mathrm{CO}_{2}, \mathrm{O}_{2}\right.$, $\mathrm{CO}, \mathrm{THC}$, and $\mathrm{NO}_{\mathrm{x}}$ ) were measured with an emissions analysis system (Horiba MEXA-7100DEGR). The oxygen molar fraction in the unburned charge was estimated by assuming that the EGR (both internal and external) was composed of products of complete combustion $\left(\mathrm{CO}_{2}, \mathrm{H}_{2} \mathrm{O}, \mathrm{O}_{2}\right.$, and $\left.\mathrm{N}_{2}\right)$ at the measured $\phi$.

The internal residual fraction, defined as the mass remaining in the cylinder from the previous cycle relative to the total mass of the trapped charge (including fuel, air, external EGR, and internal residual gases), was estimated for each cycle using the method of Fitzgerald et al. [29]. With this method, a maximum uncertainty of $\pm 5 \%$ in the measured cylinder pressure at intake valve closing (IVC) corresponds to a $\pm 2-3 \%$ uncertainty in the residual gas fraction and an associated average cylinder temperature uncertainty of $\pm 30 \mathrm{~K}$ near TDC. This uncertainty is largely expected to be systematic and not affect the observed experimental trends. Additional uncertainties of key experimental measurements 
include $\pm 1 \%$ for peak cylinder pressure, $\pm 2 \%$ for engine-out $\mathrm{NO}_{\mathrm{x}}$ emissions, and $\pm 0.2 \%$ for fuel mass

187 flow rate.

A two-zone heat release analysis was used to estimate residual fractions, in-cylinder temperatures, and combustion rates. Details of the analysis as well as validation results can be referenced in Ortiz-Soto et al. [30]. For each cycle, a modified Woschni heat transfer correlation [31] with variable mixture properties was used to calculate the gross rate of heat release and cumulative gross heat release.

192 From these results, combustion parameters such as phasing (CA50) and ringing intensity were calculated 193 on a cyclic basis. Average values of these and other parameters over the 200 recorded cycles were then 194 calculated. Ringing intensity, defined by Eng [32], was limited to an average of less than $5.0 \mathrm{MW} / \mathrm{m}^{2}$, 195 while the coefficient of variation $(\mathrm{CoV})$ of $\mathrm{IMEP}_{\mathrm{n}}$ was less than $3 \%$ when setting the baseline HCCI conditions, discussed in Section 2.4.

\subsection{Modeling framework}

To support the experimental analysis, simulations were conducted with the 3-D CFD code KIVA3V [33]. The KIVA-CFMZ model formulation chosen has been discussed in detail elsewhere [34, 35]; it simulates turbulent flame propagation using the Coherent Flamelet model $(\mathrm{CF})[36,37]$, while detailed

201 chemistry is simulated using the fully coupled Multi-Zone approach (MZ) [38]. This model has been tuned to accurately reproduce the experimentally measured cylinder pressure data from the current engine for a variety of SI, HCCI, and SACI operating conditions and has been validated by Middleton et al. [34, $20435]$.

Open cycle simulations were conducted with the KIVA-CFMZ model using a 156,000 cell detailed 3-D mesh with moving valves and piston corresponding to the geometry of the metal engine used

207 in this study. A visual representation of the mesh is shown in Figure 1. The KIVA simulations were configured to match the experimental operating conditions of interest and were initialized at $640^{\circ} \mathrm{bTDC}$ of combustion, during the expansion stroke of the previous engine cycle, using estimates of the 
211 and exhaust manifolds were imposed from the high speed manifold pressure measurements of the

212 experiments. For this work, the simulations were non-reacting and were performed up to the time of

213 spark to investigate flows and thermodynamic properties in the vicinity of the spark plug.

214 Flow turbulence was modeled using the standard $k-\varepsilon$ formulation for RANS, which reports the

215 statistical mean turbulence values but is incapable of capturing stochastic scalar fluctuations within the

216 domain that may result in cyclic variability. The initial turbulent flow field was imposed from a motored

217 simulation of a complete $720^{\circ} \mathrm{CA}$ engine cycle. Fuel injection was modeled using the high-pressure

218 swirl injector model of Chryssakis [39], which accounts for both the primary and secondary atomization

219 of fuel as well as the transition of the initial pre-swirl spray with a solid cone to the steady state behavior

220 of the main injection event with a hollow-cone structure. The injector model has previously been

221 validated and showed good agreement with experimental PLIF (planar laser-induced fluorescence)

222 measurements in an optical engine [40].

\section{$223 \quad 2.4$ Experimental procedure}

224 The current study investigates the response of an otherwise auto-igniting mixture to spark

225 ignition. For all experiments, the fueling rate was held constant at $12.5 \mathrm{mg} / \mathrm{cycle}$, resulting in an

226 approximately constant load of $\sim 4$ bar $(0.4 \mathrm{MPa}) \mathrm{IMEP}_{\mathrm{n}}$ at an engine speed of $2000 \mathrm{rpm}$. Three HCCI

227 operating conditions at varying ratios of air to EGR dilution were established as baseline conditions

228 without using spark assist. To increase the potential sensitivity to spark timing, the conditions were

229 selected near the high load limit of the HCCI combustion regime [9] with the fuel-to-charge equivalence

230 ratio $\left(\phi^{\prime}\right)$ held constant at $\phi^{\prime} \approx 0.38$. The definition of $\phi^{\prime}$ is given in Eq. 1 as

$231 \quad \phi^{\prime} \equiv \frac{F /(A+E G R)}{(F / A)_{S T}}=\frac{\phi(1-E G R)}{\left[1+\phi \cdot E G R \cdot(F / A)_{S T}\right]} \cong \phi(1-E G R)$

232 where the masses of fuel, air, and residual gas are denoted by $F, A$, and $E G R$ respectively. Here, $\phi$ is the

233 fuel-to-air equivalence ratio, the subscript $S T$ denotes stoichiometric conditions, and $E G R$ is the total in-

234 cylinder residual gas fraction, which can include both internal and external EGR. The approximation 
holds because the stoichiometric fuel-air ratio for gasoline is $\sim 0.07$, resulting in a denominator close to 1 .

236 Essentially, $\phi^{\prime}$ is a measure of the dilution level of the charge by air and EGR and approximates engine

237 load (relative to full load) for unthrottled naturally-aspirated dilute operating conditions [9].

The three baseline HCCI experiments were performed with the fixed engine parameters listed in

239 Table 2. The first experiment (Case 1), shown in Table 3, used no external EGR. The intake air 240 temperature was held constant at $45^{\circ} \mathrm{C}$, and the $\mathrm{NVO}$ was set to $152^{\circ} \mathrm{CA}$ to obtain a thermal environment in which combustion phasing (CA50) occurred at $\sim 8^{\circ}$ after top dead center (aTDC). This combustion phasing was chosen to provide near maximum thermal efficiency for HCCI combustion [41].

243 Case 1 had a total dilution level of $\sim 63 \%$ by mass ( $40 \%$ from internal residual and the remaining $23 \%$ 244 from excess air), corresponding to $\phi=0.62$ and an estimated $\mathrm{O}_{2}$ molar fraction of $15.6 \%$ in the unburned mixture. The engine was operated unthrottled at this condition with the exhaust pressure $5 \mathrm{kPa}$ above the intake pressure. Throughout the experiments, the valve timings were held constant to minimize the impact of flow and mixing variations associated with varying NVO on the results [42]. Cases 2 and 3, shown in Table 3, external EGR was incorporated into the incoming diluent mixture while holding the total charge mass (fuel + air + EGR) constant. As external EGR was added, a portion of the incoming air was replaced with products of combustion, decreasing the in-cylinder $\mathrm{O}_{2}$ concentration. To 252 compensate for the resulting changes in the end of compression temperature caused by a decreasing 253 specific heat ratio and to maintain CA50 at $\sim 8^{\circ}$ aTDC, the intake charge temperature was increased with 254 increasing external EGR. The intake and exhaust pressures were also increased by up to $8 \mathrm{kPa}(0.08 \mathrm{bar})$ 255 to maintain total charge mass by offsetting small changes in the incoming charge density. The increase in 256 exhaust pressure was estimated to cause a 3\% absolute increase in the internal residual fraction relative to 257 Case 1. With this procedure, the cylinder pressures prior to combustion differed by less than $2 \%$ between 258 the three Cases. intake temperature and intake pressure, corresponding to $\phi=0.97$. Case 2 used intermediate settings to 
Cases 1 and 3. The three Cases were phased similarly, yet the $10 \%$ to $90 \%$ mass fraction burn duration

262 increased by $2.3^{\circ} \mathrm{CA}(27 \%)$ with the addition of external EGR, leading to a $\sim 40 \%$ decrease in ringing 263 intensity and a $\sim 50 \%$ increase in $\mathrm{CoV}$ of $\mathrm{IMEP}_{\mathrm{n}}$ (shown in Table 3), similar to results from previous 264 HCCI studies [22, 25].

Once the baseline HCCI Cases were established, spark timing was applied at $30^{\circ} \mathrm{bTDC}$ and then advanced in increments of $10^{\circ} \mathrm{CA}$ for all three Cases, continuing to $120^{\circ} \mathrm{bTDC}$ for Case 1 . The

267 combustion phasing was not optimized for these experiments, as the goal was to investigate the 268 differences in combustion response behavior between the HCCI and SACI modes of operation. With this 269 procedure, the sensitivity of combustion characteristics (e.g. CA50) to variations in spark advance was 270 quantified and the effects of flame propagation on heat release behavior were deduced. If flames were 271 ineffective and auto-ignition prevailed, the combustion continued to exhibit the baseline HCCI phasing $272\left(\sim 8^{\circ}\right.$ after TDC) over the range of spark timings. This method differed from previous SI engine studies 273 that relied on incomplete combustion or partial misfire to determine flame limits $[8,15,21]$ and allowed 274 for the investigation of flame behavior at ultra-dilute operating conditions.

\section{3. Results and discussion}

2763.1 Effects of spark advance on mean and cyclic combustion behavior

277 Figure 2 shows the CA50 response of each cycle of the baseline HCCI Cases to spark advance.

278 The diamond symbols represent the mean of 200 consecutive cycles, while each " $\mathrm{x}$ " is the CA50 279 measurement for a given cycle. The baseline HCCI Cases (where no spark was used) are presented for 280 reference, labeled with a spark timing of $0^{\circ}$ aTDC. The dashed horizontal lines represent the \pm 2 standard 281 deviation $(\sigma)$ spread in CA50 for the baseline HCCI Cases.

While previous experimental studies showed SACI combustion phasing to advance with 283 advancing spark [1, 2, 5], Figure 2 shows that the mean phasing is not affected for every Case and spark 284 timing. The most air dilute Case 1 shows the most sensitivity to spark assist, with a continuous advance 285 in the mean combustion phasing up to a spark timing of $90^{\circ}$ bTDC before returning to the initial HCCI 
phasing at a spark advance of $120^{\circ}$ bTDC. The mean CA50 of Case 2 shows a weak response to spark advance before returning to the initial phasing at a spark timing of $70^{\circ}$ bTDC. The most EGR dilute Case 3 shows no significant change in mean CA50 from the HCCI phasing as spark advances. Additionally, the distributions in CA50 vary considerably among the conditions in Fig. 2. The Case 3 conditions, for example, have a similar CA50 distribution to the HCCI conditions, while the Case 1 conditions show a dramatically increased CA50 distribution as the mean CA50 advances with spark timing.

Figure 3 provides histograms of the distributions in CA50 for each condition presented in Fig. 2.

293 For the Case 1 conditions (Fig. 3a), the increased cyclic variation in CA50 with spark advance is quite 294 noticeable; not only does the mean CA50 advance with spark, but the spread in the CA50 distribution 295 increases substantially. Even for the most advanced spark timing case at $120^{\circ} \mathrm{bTDC}$, where the average 296 CA50 has returned to the initial HCCI phasing, several cycles still occur with very early CA50 timing. 297 For Case 2 (Fig. 3b), the mean CA50 advances moderately with spark advance up to $60^{\circ}$ bTDC and the 298 distribution widens; however, as the spark is advanced to the earliest timings, the distribution becomes more HCCI-like. For the Case 3 conditions (Fig. 3c), the mean CA50 and the distributions of CA50 do not vary noticeably as the spark is advanced, indicating that the combustion process remains HCCI-like even with spark ignition.

The cyclic variation in CA50 and combustion behavior for a given condition is further evident in

303 Figure 4, which compares the heat release profiles of three individual cycles (out of 200) for Case 1 at a 304 spark advance of $90^{\circ}$ bTDC. The data are from the cycles with the most advanced CA50, the most 305 retarded CA50, and the CA50 that falls closest to the mean value from the 200 recorded cycles. The 306 difference in CA50 between the most advanced cycle and the most retarded cycle is $\sim 18^{\circ} \mathrm{CA}$. The heat 307 release profile of the latest cycle resembles that of HCCI combustion, indicating that flame propagation 308 potentially failed or was ineffective. In contrast, the most advanced cycle clearly demonstrates a 309 significant portion of gradual heat release prior to auto-ignition, consistent with flame propagation and 310 previous observations of SACI [1-3]. 
312 estimated using the point of maximum positive curvature in the heat release rate (indicated in Fig. 4). The

313 maximum curvature was calculated using the first and second derivatives of the heat release rate and has

314 been used in previous studies [25, 30, 43] to define the transition point between flame propagation and 315 auto-ignition in SACI combustion. It is assumed that the transition is instantaneous, and SACI 316 combustion modeling [12] and SACI optical engine experiments [3, 4] have indicated that this is a 317 reasonable approximation.

318 Figure 5 shows the fraction of flame-based heat release as a function of combustion phasing for 319 each cycle of the Case 1 conditions in Fig. 3a. The dotted lines in each plot of Fig. 5 represent the range 320 in the fraction of flame consumption ( 4-10\%) that was estimated for the 200 cycles of HCCI data, even 321 though no flames were present. This range is the result of using the maximum curvature in the heat 322 release rate to signal the start of auto-ignition, which for HCCI is associated with intermediate 323 temperature heat release prior to thermal runaway [44]. For cycles with flame consumption levels at or 324 below $10 \%$, the overall heat release resembles that of HCCI, and it is difficult to assess whether or not 325 flames are present. Therefore, there is uncertainty in the nature of the combustion process for flame 326 consumption levels below this threshold. Beyond this level however, it is clear in Fig. 5 that combustion 327 phasing is proportional to the estimated fraction of flame-based heat release. This observation is 328 consistent with the conceptual model that spark-initiated flames further compress the surrounding 329 unburned mixture, thereby advancing the timing of auto-ignition and CA50. While not shown in Fig. 5, 330 similar trend-wise behavior was seen for the Case 2 and Case 3 conditions, but with much lower peak 331 fractions of flame-based heat release. Case 2 conditions up to spark timings of $80^{\circ}$ bTDC exhibited 332 multiple cycles of increased flame-based heat release (compared to HCCI), while Case 3 conditions 333 exhibited HCCI-like fractions for all spark timings.

334 Figure 6 provides additional insight into the combustion variability and its effects. Figure $6 a$ 335 shows $\mathrm{CoV}$ of $\mathrm{IMEP}_{\mathrm{n}}$ as a function of spark timing for every case, while Figure $6 \mathrm{~b}$ shows the 336 corresponding $\mathrm{NO}_{\mathrm{x}}$ emissions. For Case 1 conditions at spark timings up to $60^{\circ} \mathrm{bTDC}$, Figure 6a 
337 indicates that the CoV of $\mathrm{IMEP}_{\mathrm{n}}$ is marginally affected by the increased spread in both CA50 and the

338 fraction of flame-based heat release noted in Fig. 5. As the spark advances from $70^{\circ}$ to $105^{\circ}$ bTDC for 339 the Case 1 conditions, the spread in CA50 and the fraction of flame-based heat release continue to 340 increase, and the $\mathrm{CoV}$ of $\mathrm{IMEP}_{\mathrm{n}}$ increases noticeably. For even earlier spark timings at $115^{\circ}$ and $120^{\circ}$ 341 bTDC, the maximum fraction of flame-based heat release in Fig. 5 remains high; however, the number of 342 combustion events with high levels of flame-based heat release decreases, the CA50 distribution becomes 343 more HCCI-like, and the $\mathrm{CoV}$ of $\mathrm{IMEP}_{\mathrm{n}}$ decreases. Figure 6a indicates that for highly dilute mixtures 344 near the flammability limit, spark assist does not always increase combustion stability. This result differs 345 from previous studies which showed that spark assist consistently improved the stability of HCCI 346 combustion $[1,5]$.

347 The effect on $\mathrm{NO}_{\mathrm{x}}$ of the increased fraction of flame-based heat release with combustion advance 348 is shown in Figure 6b. For the Case 1 conditions, the $\mathrm{NO}_{\mathrm{x}}$ emissions increase notably as spark is 349 advanced from TDC, with the maximum $\mathrm{NO}_{\mathrm{x}}$ emissions observed at a spark advance of $105^{\circ} \mathrm{bTDC}$. The 350 increase in $\mathrm{NO}_{\mathrm{x}}$ is attributed to increased combustion temperatures which can occur due to two 351 mechanisms. Since flame propagation is inherently slower than auto-ignition, the burned gas within the 352 flame is expected to reside at elevated temperatures for longer periods of time, especially when those 353 flames are initiated earlier in the cycle. Additionally, the increased $\mathrm{NO}_{\mathrm{x}}$ emissions could be associated 354 with increased peak mean gas temperatures resulting from more advanced combustion. As the Case 1 355 conditions become more HCCI-like at spark timings earlier than $105^{\circ} \mathrm{bTDC}$, the $\mathrm{NO}_{\mathrm{x}}$ emissions decrease 356 to their initial values.

\subsection{Estimating thermodynamic properties and flame speeds}

There are two probable scenarios for the conditions that show little response to spark timing: (1)

359 The spark-initiated flames are quenched shortly after spark, or (2) flames can be successfully initiated and propagate, but the flames do not have sufficient time to noticeably impact combustion phasing or heat 
release rate prior to auto-ignition. The goal of the following analysis is to determine the likelihood of either scenario for each operating condition in order to explain the observed experimental behavior.

First, the mean global thermodynamic and compositional states of each mixture at the time of 364 spark ignition were estimated from heat release analysis. The global compositional states are listed in 365 Table 3, and the results for the mean unburned gas temperature $\left(T_{u}\right)$ at the time of spark are presented in 366 Figure $7 \mathrm{a}$, which show that $T_{u}$ decreases by $\sim 300 \mathrm{~K}$ as spark timing advances from $30^{\circ} \mathrm{bTDC}$ to over $367100^{\circ}$ bTDC. The lower temperatures associated with spark advance would potentially increase the 368 difficulty of initiating a flame. On the other hand, the lower $T_{u}$ would lead to longer end-gas ignition 369 delay times, which would allow more time for flame propagation to occur prior to auto-ignition. The most EGR dilute Case (Case 3) exhibits consistently higher $T_{u}$ 's (by 20-30 K) for a given spark timing, which resulted from the increased intake temperature necessary to maintain constant HCCI combustion 372 phasing at this equivalence ratio.

The estimated mean global unburned mixture properties and the measured cylinder pressures at

374 the time of spark were used to estimate the corresponding burned gas temperature $\left(T_{b}\right)$, laminar flame 375 speed $\left(S_{L}\right)$, and laminar flame thickness $(\delta)$ using the correlation of Middleton et al. [13], which was 376 developed from laminar flame simulations that were validated with experimental flame data covering a 377 broad range of pressure, unburned gas temperature, and equivalence ratio conditions for air and EGR 378 dilute mixtures $[10,13]$. Although the correlation was developed from iso-octane laminar flame 379 predictions, the results are expected to be similar for gasoline given the comparable laminar burning 380 velocities and ignition delay times of the two fuels $[45,46]$.

Estimates of $T_{b}$ and $S_{L}$ using the global mixture properties at the time of spark are presented in 382 Figures $7 \mathrm{~b}$ and $7 \mathrm{c}$, respectively. As spark advances the global $T_{b}$ shows a decreasing trend similar to the 383 global $T_{u}$ in Fig. 7a. Despite having higher $T_{u}$ 's at the time of spark, the more EGR dilute Case 3 384 conditions have the lowest $T_{b}$ 's (by $\sim 70 \mathrm{~K}$ ) due to the increased mixture heat capacity. The estimated 385 global $T_{b}$ 's for Cases 1 and 2 are closer in magnitude. The global $S_{L}$ results in Fig. 7c show that for a 386 given spark timing, the EGR dilute Case 3 conditions have the lowest predicted $S_{L}$ while the more air 
dilute Case 1 conditions have the highest predicted $S_{L}$. The results may explain why Case 1 showed the greatest sensitivity to spark advance, as the estimated flame speeds are highest for Case 1.

Due to the nature of the fuel delivery system and valve strategy used in this engine study, it is likely that compositional stratification played a role in the combustion behavior, especially at the earliest spark timings. Thus, global parameters may not be the most relevant metrics to use for comparison with the observed trends. As a consequence, estimates for local conditions were also considered. The previously discussed KIVA-3V model of the engine was used to determine the pressure, temperature, 394 composition, and turbulence characteristics for each Case within a $1 \mathrm{~cm}^{3}$ volume surrounding the spark 395 plug at the time of spark. The cylinder pressures predicted by KIVA-3V for each Case at the time of spark typically differed from the experimentally measured values by no more than $1-2 \%$.

The estimated local unburned gas temperatures near the spark plug are presented in Figure 8a. The local $T_{u}$ follows a similar trend to the global results shown in Fig. 7a, with the EGR dilute Case 3 exhibiting the highest $T_{u}$ for a given spark timing. The magnitudes of the local $T_{u}$ are elevated by $\sim 3-10 \%$ $(\sim 30-60 \mathrm{~K})$ compared to the global estimates presented in Fig. 7a since they were determined in the core of the combustion chamber. The results for the local fuel-to-air equivalence ratio $(\phi)$ and fuel-to-charge equivalence ratio $\left(\phi^{\prime}\right)$ are presented in Figures $8 \mathrm{~b}$ and $8 \mathrm{c}$, respectively. The increase in $\phi$ and $\phi^{\prime}$ with 403 spark advance indicates an increased concentration of fuel near the spark plug at earlier crank angles, 404 likely due to insufficient mixing of the injected fuel and air/EGR charge. Case 3 consistently has the 405 highest $\phi$ since it has the highest EGR fraction, but both $\phi$ and $\phi^{\prime}$ at the time of spark increase in a 406 similar manner for all three Cases with spark advance. While fuel stratification appears to be the 407 dominant effect, the KIVA results suggest that insufficient mixing of the residual gases retained during 408 NVO and the incoming air/EGR charge could also be contributing to the behavior. The details of the mixing process are complex and beyond the scope of the current work.

The $T_{b}$ and $S_{L}$ determined from the local state using the correlation in [13] are shown in Figures

$4119 \mathrm{a}$ and 9b, respectively, and demonstrate substantially different behavior compared to the global analysis 
412 presented in Fig. 7. Despite the decrease in the local $T_{u}$ with spark advance, $T_{b}$ increases for all of the

413 Cases due to the increased $\phi^{\prime}$ of the local mixture, provided that the local $\phi$ is not rich. This is apparent 414 for Case 3 at a spark timing of $60^{\circ} \mathrm{bTDC}$, where although Case 3 has the highest $T_{u}$ and similar $\phi^{\prime}$ to the 415 other Cases, it exhibits the lowest $T_{b}$ due to a lack of air near the spark plug, preventing the complete 416 release of the local charge's chemical energy. For spark timings at or later than $50^{\circ} \mathrm{bTDC}$, where all of

417 the mixtures are stoichiometric or lean at the spark plug, the $T_{b}$ 's are similar for similar $T_{u}$ and $\phi^{\prime}$, as 418 expected. The estimated local $S_{L}$ 's in Fig. 9b show a similar behavior to the local $T_{b}$. The highest 419 estimated values for $S_{L}$ are for the Case 1 conditions, which also showed the greatest sensitivity to spark 420 advance experimentally. The Case 2 conditions show a decrease in $S_{L}$ around the same spark timing that 421 the spark ceased having a noticeable effect on combustion behavior. The most EGR dilute Case 3 422 conditions, which showed no reaction to the spark event, exhibit the lowest predicted $S_{L}$ for a given spark 423 timing.

\subsection{Assessing flame limit behaviors}

As mentioned previously, two conditions limiting the effectiveness of the flame are expected within the current study, namely quenching and limited time for the flame to noticeably affect the overall

427 combustion process. Regarding the latter limiting condition, Figure 10a presents the ratio of ignition 428 delay time $\left(\tau_{I D}\right)$ to flame time $\left(\tau_{F}\right)$ at the time of spark for each condition. The ignition delay time $\left(\tau_{I D}\right)$ 429 was calculated using the mean cylinder conditions at the time of spark and the iso-octane ignition delay 430 correlation of $\mathrm{He}$ et al. [47]. It provides a qualitative estimate for the amount of time it would take the 431 global mixture to auto-ignite at these conditions, neglecting the effects of piston and/or flame front 432 compression, which will tend to reduce the ignition delay. Neglecting these effects, $\tau_{I D}$ represents a 433 conservative upper bound when calculated at the time of spark.

The flame time $\left(\tau_{F}\right)$, which represents the time it takes for the flame to travel the characteristic distance equal to its thickness, was estimated using $\tau_{F}=\delta / S_{L}$ where the laminar flame speed $\left(S_{L}\right)$ and the laminar flame thickness $(\delta)$ were determined using the local state conditions near the spark plug at the 
time of spark and the correlations of Middleton et al. [13]. The ratio $\tau_{I D} / \tau_{F}$ gives an estimate for the number of flame thicknesses traveled during the ignition delay period, and the fraction of flame-based heat release would be expected to increase with increasing $\tau_{I D} / \tau_{F}$ for SACI combustion in the absence of

440 factors such as stratification or flame quenching. The results in Fig. 10a suggest that at more retarded 441 spark timings the ignition delay time becomes relatively short compared to the flame time. Trend-wise, 442 this result is expected given that combustion is starting closer to top dead center. The ratio is smallest for 443 the Case 3 condition at a spark advance of $30^{\circ} \mathrm{bTDC}$, where no substantial response to spark assist was 444 seen experimentally.

To determine a value for $\tau_{I D} / \tau_{F}$ that corresponds to a detectably large fraction of flame-based heat

447 was collected on the same engine under similar operating conditions, where the fraction of flame-based heat release was manipulated via changes to the unburned charge temperature and spark timing at constant combustion phasing. Figure $10 \mathrm{~b}$ shows the estimated $\tau_{I D} / \tau_{F}$ for the dataset from Olesky et al. [43] plotted against the mean estimated fraction of flame-based heat release. The trend line is extrapolated down to "flame-based" heat release levels characteristic of HCCI combustion, i.e. a maximum of $10 \%$. The corresponding $\tau_{I D} / \tau_{F}$ is $\sim 50$, indicating that even if flames were present under these conditions, they are not likely to be detected with heat release analysis due to the uncertainty in distinguishing between flames and intermediate temperature heat release of the end-gas.

In Fig. 10a, the estimated $\tau_{I D} / \tau_{F}$ ratios approach the $\tau_{I D} / \tau_{F}=50$ limit at the latest spark timing of $30^{\circ} \mathrm{bTDC}$, but are still greater than this value (note that the scale of the y-axis is logarithmic). While 457 approximate, this result suggests that all of the conditions likely have $\tau_{I D} / \tau_{F}$ values that are sufficiently 458 high to produce a noticeable increase in the average fraction of flame-based heat release and advance 459 combustion compared to the HCCI conditions, provided that flames can exist. For the conditions where $460 \tau_{I D} / \tau_{F}>50$ and the mean combustion behavior shows little variation compared to the HCCI conditions 461 (e.g. all of the Case 3 conditions), it is reasonable to infer that flame quenching has occurred, at least for a majority of the cycles, given the relatively long ignition delay times available for flame propagation. 
Having established flame quenching as the likely cause of combustion non-response and flame 465 limiting behavior for this dataset, the estimated global and local state conditions were plotted on the 466 Leeds diagram [20] in Figure 11 to compare the data to the theoretical regimes of turbulent combustion. 467 The Leeds diagram represents the influence of turbulence on the likelihood of flame quench by flame468 turbulence interactions. The flame characteristics $\left(S_{L}\right.$ and $\left.\delta\right)$ determined from the correlation in 469 Middleton et al. [13] based on the estimates for the global state conditions in the cylinder are shown in 470 Figure 11a, while the estimates based on the local flame data determined using the KIVA-3V results in 471 the vicinity of the spark plug are plotted in Figure 11b. Additionally, the KIVA-3V engine model was 472 used to estimate the root mean square (rms) turbulent velocity $\left(u^{\prime}\right)$ and integral length scale $(L)$ within the $4731 \mathrm{~cm}^{3}$ volume around the spark plug at the time of spark. Since the turbulence characteristics near the 474 spark plug are insensitive to changes in mixture composition, the estimated values for $u^{\prime}$ and $L$ were used 475 for both the global state analysis (Fig. 11a) and the local state analysis (Fig. 11b). Within the range of 476 experimental spark timings, the values of $u^{\prime}$ and $L$ ranged from $370-450 \mathrm{~cm} / \mathrm{s}$ and $0.39-0.65 \mathrm{~cm}$, 477 respectively. The theoretical flame quench limits of Abdel-Gayed et al. [20,48] and Roberts et al. [17] 478 are also included in Figs. 11a and $11 \mathrm{~b}$ as a function of the Karlovitz number $(\mathrm{Ka})$ as defined by Abdel479 Gayed et al. [20, 48] in Eq. 2.

$480 \quad K a=0.157\left(\frac{u^{\prime}}{S_{L}}\right)^{3 / 2}\left(\frac{L}{\delta}\right)^{-1 / 2}$

481 Also included in both figures are the SACI data shown in Fig. 10b from Olesky et al. [43] where viable 482 flames were experimentally observed on a cyclic basis, as well as some stable stoichiometric throttled SI 483 data that were collected on the same engine. The flame characteristics for these SACI and SI points were 484 modeled in KIVA-3V by Middleton [35].

485 Due to high cyclic variability, it was decided that the conditions in Fig. 2 in which the mean 486 CA50 fell outside $\pm 2 \sigma$ of the corresponding HCCI CA50 distribution were clearly affected by the spark 
event, and therefore, labeled as unquenched. In Figures $11 \mathrm{a}$ and $11 \mathrm{~b}$, these conditions are indicated by open symbols. The conditions that were defined as quenched have a mean CA50 inside $\pm 2 \sigma$ of the HCCI

489 CA50 spread and are shown with closed symbols in both figures. The majority of the quenched data 490 points lie in the appropriate flammability region of the Leeds diagram [17, 20], but the local conditions in 491 Fig. 11b have better agreement with the theoretical regimes of turbulent flame propagation than the global 492 conditions in Fig. 11a. For many of the air dilute Case 1 conditions, the Karlovitz numbers determined 493 from the global state are 20-40 times higher than the $K a$ calculated from the local state. The findings 494 indicate the shortcomings of the global state analysis and the importance of compositional stratification to 495 the effectiveness of spark assist under the observed experimental SACI conditions. From a practical standpoint, the results suggest that in-cylinder stratification, achieved through various mixing and/or fuel injection strategies, can be used as an additional means of SACI combustion control.

\section{Conclusions}

In this study, the ability of flames to affect the combustion phasing of highly dilute mixtures with varying ratios of air to EGR dilution was explored. The conditions presented were selected to fall near the boundary between the HCCI and SACI combustion regimes at approximately 4 bar $(0.4 \mathrm{MPa})$ net indicated mean effective pressure $\left(\mathrm{IMEP}_{\mathrm{n}}\right)$. Starting with three baseline HCCI conditions at constant chemical energy content and combustion phasing, but with varying fractions of EGR, spark assist was were drawn:

1. The sensitivity of combustion phasing to spark advance was in part a function of dilution method. At the highest level of EGR dilution, combustion phasing was not affected by spark assist, while at the lowest level of EGR dilution, combustion phasing was noticeably advanced by spark assist. At a spark advance of $80^{\circ}$ before TDC, for example, the combustion phasing of the most air dilute mixture $(\phi=0.62)$ advanced by $\sim 8^{\circ} \mathrm{CA}$ on average compared to the HCCI phasing, while the most EGR dilute mixture $(\phi=0.97)$ showed almost no response to the spark event, despite 
the fact that the unburned gas temperature in the vicinity of the spark plug was highest for the EGR dilute mixture. For these conditions, the combustion behavior resembled that of HCCI.

2. For a distribution of cycles at a given spark timing, the most advanced cycles demonstrated a larger fraction of flame-based heat release and earlier end-gas auto-ignition. This observation indicated that the increased levels of dilute flame propagation and associated end-gas compression contributed to the advance in combustion phasing.

3. As the spark was advanced up to $105^{\circ}$ before TDC for the most air dilute mixture, combustion stability deteriorated and the spread in CA50 for 200 consecutive cycles increased. Alternatively, for the more EGR dilute mixtures the combustion stability remained approximately constant, regardless of spark timing. The use of spark assist, therefore, does not consistently increase the stability of dilute combustion.

4. In comparing the estimated ignition delay time $\left(\tau_{I D}\right)$ to the flame time $\left(\tau_{F}\right)$ calculated in part with KIVA-3V predictions for each condition, it was found that $\tau_{I D}$ increased compared to $\tau_{F}$ as spark advanced. This indicated that, at more advanced spark timings, the absence of deflagrative heat release and combustion advance likely resulted from flame quench rather than a lack of time for the flame to be effective.

5. The results of a detailed KIVA-3V model of the engine indicated that the in-cylinder mixture became increasingly stratified at more advanced crank angles. For a given spark timing and turbulent flow field, the flame characteristics estimated from the local conditions near the spark plug were more consistent with the theoretical regimes of turbulent combustion presented in the Leeds diagram [20] than the flame characteristics estimated from the global cylinder state. This finding indicates that a bulk properties analysis fails to explain the experimental observations, and in-cylinder stratification can highly affect the behavior and effectiveness of SACI within a practical combustion device. 


\section{Acknowledgements}

The authors acknowledge the generous support of the U.S. Department of Energy (contract DEEE0000203, “A University Consortium on Efficient and Clean High Pressure Lean Burn (HPLB) Engines"). The authors thank Elliott Ortiz-Soto for his assistance with the analysis.

541

542

543

544

545

546

547

548

549

\section{References}

[1] Wang Z, Wang J, Shuai S, He X, Xu F, Yang D, Ma X. Research on spark induced compression ignition (SICI). SAE 2009-01-0132; 2009.

[2] Manofsky L, Vavra J, Assanis D, Babajimopoulos A. Bridging the gap between HCCI and SI: Spark-assisted compression ignition. SAE 2011-01-1179; 2011.

[3] Persson H, Hultqvist A, Johansson B, Remón A. Investigation of the early flame development in spark assisted HCCI combustion using high speed chemiluminescence imaging. SAE 2007-010212; 2007.

[4] Reuss DL, Kuo T-W, Silvas G, Natarajan V, Sick V. Experimental metrics for identifying origins of combustion variability during spark-assisted compression ignition. Int J Eng Res 2008;9(5):40934.

[5] Zigler BT, Keros PE, Helleberg KB, Fatouraie M, Assanis D, Wooldridge M. An experimental investigation of the sensitivity of the ignition and combustion properties of a single-cylinder research engine to spark-assisted HCCI. Int J Eng Res 2011;12(4):353-75.

[6] Daw CS, Wagner RM, Edwards KD, Green JB. Understanding the transition between conventional spark-ignited combustion and HCCI in a gasoline engine. Proc Combust Inst 2007;31(2):2887-94.

[7] Hyvönen J, Haraldsson G, Johansson B. Operating conditions using spark assisted HCCI combustion during combustion mode transfer to SI in a multi-cylinder VCR-HCCI engine. SAE 2005-01-0109; 2005.

[8] Quader A. What limits lean operation in spark ignition engines - flame initiation or propagation? SAE 760760; 1976. 
562 [9] Lavoie GA, Martz J, Wooldridge M, Assanis D. A multi-mode combustion diagram for spark assisted compression ignition. Combust Flame 2010;157(6):1106-10.

564 [10] Martz JB, Middleton RJ, Lavoie GA, Babajimopoulos A, Assanis DN. A computational study and correlation of premixed isooctane-air laminar reaction front properties under spark ignited and spark assisted compression ignition engine properties. Combust Flame 2011;158(6):1089-96.

567 [11] Huang Y, Sung CJ, Eng JA. Dilution limits of $n$-butane/air mixtures under conditions relevant to 568 HCCI combustion. Combust Flame 2004;136(4):457-66.

569 [12] Martz JB, Lavoie GA, Im HG, Middleton RJ, Babajimopoulos A, Assanis DN. The propagation of 570 a laminar reaction front during end-gas auto-ignition. Combust Flame 2012;159(6):2077-86.

571 [13] Middleton RJ, Martz JB, Lavoie GA, Babajimopoulos A, Assanis DN. A computational study and 572

[14] Herweg R, Maly R. A fundamental model for flame kernel formation in S.I. engines. SAE 922243; 575 1992.

576

[15] Dai W, Russ SG, Trigui N, Tallio KV. Regimes of premixed turbulent combustion and misfire modeling in SI engines. SAE 982611; 1998.

578 [16] Poinsot T, Veynante D, Candel S. Quenching processes and premixed turbulent combustion 579 diagrams. J Fluid Mech 1991;228:561-606.

580 [17] Roberts WL, Driscoll JF, Drake MC, Goss LP. Images of the quenching of a flame by a vortex - To quantify regimes of turbulent combustion. Combust Flame 1993;94(1-2):58-69.

582 [18] Williams FA. Criteria for existence of wrinkled laminar flame structure of turbulent premixed flames. Combust Flame 1976;26:269-70.

[19] Driscoll JF. Turbulent premixed combustion: Flamelet structure and its effect on turbulent burning velocities. Prog Energ Combust Sci 2008;34(1):91-134.

[20] Abdel-Gayed RG, Bradley D, Lung FK-K. Combustion regimes and the straining of turbulent premixed flames. Combust Flame 1989;76(2):213-18. 
[21] Peterson B, Reuss DL, Sick V. High-speed imaging analysis of misfires in a spray-guided direct injection engine. Proc Combust Inst 2011;33(2):3089-96.

[22] Dec J, Sjöberg M, Hwang W. Isolating the effects of EGR on HCCI heat-release rates and NOx emissions. SAE Int J Eng 2010;2(2):58-70.

[23] Olsson J-O, Tunestal P, Ulfvik J, Johansson B. The effect of cooled EGR on emissions and performance of a turbocharged HCCI engine. SAE 2003-01-0743; 2003.

[24] Kodavasal J, Lavoie GA, Assanis DN, Martz JB. The effect of diluent composition on homogeneous charge compression ignition auto-ignition and combustion duration. Proc Combust Inst 2015;35(3):3019-26.

[25] Olesky LM, Lavoie GA, Assanis DN, Wooldridge MS, Martz JB. The effects of diluent composition on the rates of HCCI and spark assisted compression ignition combustion. Appl Energ 2014;124:186-98.

[26] Wang Z, Wang J-X, Shuai S-J, Ma Q-J. Effects of spark ignition and stratified charge on gasoline HCCI combustion with direct injection. SAE 2005-01-0137; 2005.

[27] Persson H, Pfeiffer R, Hultqvist A, Johansson B, Ström H. Cylinder-to-cylinder and cycle-to-cycle variations at HCCI operation with trapped residuals. SAE 2005-01-0130; 2005.

[28] Weinrotter M, Wintner E, Iskra K, Neger T, Olofsson J, Seyfried H, et al. Optical diagnostics of laser-induced and spark plug-assisted HCCI combustion. SAE 2005-01-0129; 2005.

[29] Fitzgerald R, Steeper R, Snyder J, Hanson R, Hessel R. Determination of cycle temperatures and residual gas fraction for HCCI negative valve overlap operation. SAE Int J Eng 2010;3(1):124-41.

[30] Ortiz-Soto EA, Lavoie GA, Martz JB, Wooldridge MS, Assanis DN. Enhanced heat release analysis for advanced multi-mode combustion engine experiments. Appl Energy 2014;136:465-79.

[31] Chang J, Güralp O, Filipi Z, Assanis D, Kuo T-W, Najt P, Rask R. New heat transfer correlation for an HCCI engine derived from measurements of instantaneous surface heat flux. SAE 2004-012996; 2004.

[32] Eng J. Characterization of pressure waves in HCCI combustion. SAE 2002-01-2859; 2002. 
614

[33] Amsden AA. KIVA-3V: A block-structured KIVA program for engines with vertical or canted valves. Los Alamos (NM): Los Alamos National Laboratory; 1997 July Report No.: LA-13313-MS. Contract No.: W-7405-ENG-36. Sponsored by the Department of Energy.

[34] Middleton RJ, Olesky LKM, Martz JB, Lavoie GA, Wooldridge MS, Assanis DN. The effect of spark timing and negative valve overlap on spark assisted compression ignition combustion heat release rate. Proc Combust Inst 2015;35(3):3117-24.

[35] Middleton RJ. Simulation of spark assisted compression ignition combustion under EGR dilute engine operating conditions [dissertation]. Ann Arbor (MI): The University of Michigan; 2014.

[36] Meneveau C, Poinsot T. Stretching and quenching of flamelets in premixed turbulent combustion. Combust Flame 1991;86(4):311-32.

[37] Baritaud TA, Duglos JM, Fusco A. Modeling turbulent combustion and pollutant formation in stratified charge SI engines. Symp (Int) Combust 1996;26(2):2627-35.

[38] Babajimopoulos A, Assanis DN, Flowers DL, Aceves SM, Hessel RP. A fully coupled computational fluid dynamics and multi-zone model with detailed chemical kinetics for the simulation of premixed charge compression ignition engines. Int J Eng Res 2005;6(5):497-512.

[39] Chryssakis C, Assanis DN. A unified fuel spray breakup model for internal combustion engine applications. Atomization Spray 2008;18(5):375-426.

[40] Chryssakis CA, Assanis DN, Lee J-K, Nishida K. Fuel spray simulation of high-pressure swirlinjector for DISI engines and comparison with laser diagnostic measurements. SAE 2003-01-0007; 2003.

[41] Lavoie G, Ortiz-Soto E, Babajimopoulos A, Martz JB, Assanis DN. Thermodynamic sweet spot for high-efficiency, dilute, boosted gasoline engines. Int J Eng Res 2013;14(3):260-78.

[42] Rothamer DA, Snyder JA, Hanson RK, Steeper RR, Fitzgerald RP. Simultaneous imaging of exhaust gas residuals and temperature during HCCI combustion. Proc Combust Inst 2009;32(2):2869-76. 
641 [43] Olesky LM, Martz JB, Lavoie GA, Vavra J, Assanis DN, Babajimopoulos A. The effects of spark 642 timing, unburned gas temperature, and negative valve overlap on the rates of stoichiometric spark $643 \quad$ assisted compression ignition combustion. Appl Energy 2013;105:407-17.

644 [44] Dec J, Yang Y. Boosted HCCI for high power without engine knock and with ultra-low NOx 645 emissions - using conventional gasoline. SAE Int J Eng 2010;3(1):750-67.

646 [45] Jerzembeck S, Peters N, Pepiot-Desjardins P, Pitsch H. Laminar burning velocities at high pressure 647 for primary reference fuels and gasoline: Experimental and numerical investigation. Combust $648 \quad$ Flame 2009;156(2):292-301.

649 [46] Babajimopoulos A, Lavoie GA, Assanis DN. On the role of top dead center conditions in the 650 combustion phasing of homogeneous charge compression ignition engines. Combust Sci Tech 2007; 2 2039(9):2039-63.

[47] He X, Donovan MT, Zigler BT, Palmer TR, Walton SM, Wooldridge MS, Atreya A. An experimental and modeling study of iso-octane ignition delay times under homogeneous charge compression ignition conditions. Combust Flame 2005;142(3):266-75.

655

656

[48] Abdel-Gayed B, Bradley D. Criteria for turbulent propagation limits of premixed flames. Combust Flame 1985;62(1):61-8.

657

658 Nomenclature

659 AKI anti-knock index

660 aTDC after top dead center

661 bTDC before top dead center

662 CA crank angle

663 CA50 combustion phasing; crank angle where 50\% of fuel mass is burned 
664 CoV coefficient of variation

$665 \delta \quad$ laminar flame thickness

666 EGR exhaust gas recirculation

667 HCCI homogeneous charge compression ignition

668 HR heat release

$669 \mathrm{IMEP}_{\mathrm{n}}$ net indicated mean effective pressure

$670 L \quad$ turbulent integral length scale

671 LTC low temperature combustion

$672 \mathrm{Ka} \quad$ Karlovitz number

673 MBT maximum brake torque

674 NVO negative valve overlap

$675 \phi$ fuel-to-air equivalence ratio

$676 \phi^{\prime} \quad$ fuel-to-charge equivalence ratio

677 rms root mean square

$678 \sigma \quad$ standard deviation

679 SACI spark assisted compression ignition

680 SI spark ignited

$681 S_{L} \quad$ laminar flame speed

$682 T_{b} \quad$ burned gas temperature

683 TDC top dead center

$684 T_{u} \quad$ unburned gas temperature

$685 \tau_{I D} \quad$ ignition delay time

$686 \tau_{F} \quad$ flame time

$687 \quad u^{\prime} \quad$ rms turbulent velocity

688

689 


\section{Figure Captions}

690

691

692

693

694

695

696

697

698

699

700

701

702

703

704

705

706

707

708

709

710

711

712

713

714

715

716

717

718

719

720

721

722

723

724

725

726

Figure 1: 3-D computational mesh used in the KIVA-CFMZ model containing 156,000 cells and corresponding to the geometry of the metal engine used in the study.

Figure 2: Response of CA50 to spark advance for the three Cases listed in Table 3. Data at $0^{\circ}$ spark timing are for the baseline HCCI conditions where no spark was used. Each dataset contains 200 consecutive cycles of pressure data. The diamond-shaped symbols are mean CA50 values. The dashed lines are $\pm 2 \sigma$ in CA50 for the HCCI conditions.

Figure 3: Histograms of CA50 containing 200 consecutive cycles for each condition presented in Figure 2 - (a) Case 1, (b) Case 2, and (c) Case 3. Spark advance (SA) values are presented in crank angle degrees before TDC.

Figure 4: Heat release profiles of three individual cycles for Case 1 at a spark advance of $90^{\circ}$ bTDC. Each curve represents an individual cycle (out of 200): the most advanced cycle (minimum CA50), the most retarded cycle (maximum CA50), and the cycle whose CA50 falls closest to the mean value. Note that the most retarded cycle resembles HCCI combustion.

Figure 5: Estimated fraction of flame-based heat release (HR) as a function of CA50 for each cycle of the Case 1 conditions shown in Figure 3a. The dashed lines represent the range of values determined from the baseline HCCI condition ( 4-10\%). The cycles with flame-based heat release above this range are advanced due to spark-induced flame propagation.

Figure 6: (a) $\mathrm{CoV}$ of $\mathrm{IMEP}_{\mathrm{n}}$ and (b) engine-out $\mathrm{NO}_{\mathrm{x}}$ emissions as a function of spark advance for each condition shown in Figure 2. Data at $0^{\circ}$ spark advance are for the baseline HCCI conditions.

Figure 7: (a) Estimated mean global values of unburned gas temperature $\left(T_{u}\right)$ at the time of spark from heat release analysis; estimated values of (b) burned gas temperature $\left(T_{b}\right)$ and (c) laminar flame speed $\left(S_{L}\right)$ determined from the mean global state at the time of spark using the correlation of Middleton et al. [13].

Figure 8: Estimated local values of (a) unburned gas temperature $\left(T_{u}\right)$, (b) fuel-to-air equivalence ratio $(\phi)$, and (c) fuel-to-charge equivalence ratio $\left(\phi^{\prime}\right)$ at the time of spark determined from the KIVA-3V engine model [34] within a $1 \mathrm{~cm}^{3}$ volume around the spark plug.

Figure 9: Estimated values of (a) burned gas temperature $\left(T_{b}\right)$ and (b) laminar flame speed $\left(S_{L}\right)$ determined from the local state at the time of spark using the laminar flame speed correlation of Middleton et al. [13].

Figure 10: (a) Ratio of ignition delay time $\left(\tau_{I D}\right)$ to flame time $\left(\tau_{F}\right)$ calculated at the time of spark for each condition. Note that the $y$-axis is a logarithmic scale. (b) $\tau_{I D} / \tau_{F}$ plotted against the mean fraction of flamebased heat release for SACI data presented in Olesky et al. [43]. Extrapolating the trend line to flamebased heat release fractions of $10 \%$ yields a value for $\tau_{I D} / \tau_{F}$ of $\sim 50$, which is the value where heat release due to the flame is projected to be indistinguishable from the intermediate temperature heat release of the end-gas.

Figure 11: Leeds diagram showing estimates of the flame characteristics using (a) the global state at the time of spark and (b) the local state in the vicinity of the spark plug determined from KIVA-3V [34] at the time of spark. Flame quenching was defined to occur for the conditions in which the mean CA50 was 
727 within $\pm 2 \sigma$ of the CA50 distribution for the baseline HCCI Cases. These conditions are represented by 728 closed markers and non-quenching conditions are represented by open markers. 
Table 1: Engine geometry

\begin{tabular}{l|l}
\hline Parameter & Value \\
\hline Displaced volume $\left(\mathrm{cm}^{3}\right)$ & 550 \\
Bore $(\mathrm{mm})$ & 86.0 \\
Stroke $(\mathrm{mm})$ & 94.6 \\
Connecting rod length $(\mathrm{mm})$ & 156.5 \\
Piston pin offset $(\mathrm{mm})$ & 0.8 \\
Compression ratio & $12.5: 1$ \\
\hline
\end{tabular}

\begin{tabular}{l|l} 
Compression ratio & $12.5: 1$ \\
\hline
\end{tabular} 
Table 2: Settings of fixed engine parameters

\begin{tabular}{l|l}
\hline Parameter & Value \\
\hline Engine speed (rpm) & 2000 \\
Fuel flow rate (mg/cycle) & 12.5 \\
Fuel injection pressure (bar) & 100 \\
Start of fuel injection ( ${ }^{\circ}$ bTDC) & 330 \\
End of fuel injection $\left({ }^{\circ}\right.$ bTDC) & 309 \\
Negative valve overlap ( $\left.{ }^{\circ} \mathrm{CA}\right)$ & 152 \\
Intake valve closing $\left({ }^{\circ}\right.$ bTDC) & 150 \\
Exhaust valve opening $\left({ }^{\circ}\right.$ aTDC) & 150 \\
Valve lift $(\mathrm{mm})$ & 6.0 \\
Engine coolant/oil temperature $\left({ }^{\circ} \mathrm{C}\right)$ & 90 \\
EGR coolant temperature $\left({ }^{\circ} \mathrm{C}\right)$ & 55 \\
Spark energy from the coil $(\mathrm{mJ})$ & 70 \\
\hline
\end{tabular}


Table 3: Unburned mixture properties of the baseline HCCI Cases with varying levels of air to EGR dilution

\begin{tabular}{|c|c|c|c|}
\hline Parameter & Case 1 & Case 2 & Case 3 \\
\hline Fuel-to-air equivalence ratio, $\phi$ & 0.62 & 0.81 & 0.97 \\
\hline Fuel-to-charge equivalence ratio, $\phi^{\prime a}$ & 0.37 & 0.38 & 0.38 \\
\hline $\begin{array}{l}\text { External EGR volumetric fraction, measured in } \\
\text { intake manifold }(\%)\end{array}$ & 0 & 21 & 31 \\
\hline External EGR mass fraction, in-cylinder $(\%)^{\mathrm{a}}$ & 0 & 12 & 17 \\
\hline Internal EGR (residual) mass fraction $(\%)^{\mathrm{a}}$ & 40 & 41 & 43 \\
\hline Total EGR mass fraction $(\%)^{\mathrm{a}}$ & 40 & 53 & 60 \\
\hline Molar $\mathrm{O}_{2}$ fraction in unburned mixture $(\%)^{\mathrm{a}}$ & 15.6 & 12.1 & 9.3 \\
\hline Intake charge temperature $\left({ }^{\circ} \mathrm{C}\right)$ & 45 & 77 & 115 \\
\hline Intake pressure (bar, absolute) & 1.0 & 1.04 & 1.08 \\
\hline Exhaust pressure (bar, absolute) & 1.05 & 1.08 & 1.12 \\
\hline Ringing intensity $\left(\mathrm{MW} / \mathrm{m}^{2}\right)$ & 3.1 & 2.4 & 1.9 \\
\hline $\mathrm{CoV}$ of $\operatorname{IMEP}_{\mathrm{n}}(\%)$ & 0.98 & 1.36 & 1.53 \\
\hline
\end{tabular}

${ }^{\text {a }}$ Derived quantities based on inferred internal EGR (residual) mass from heat release analysis 


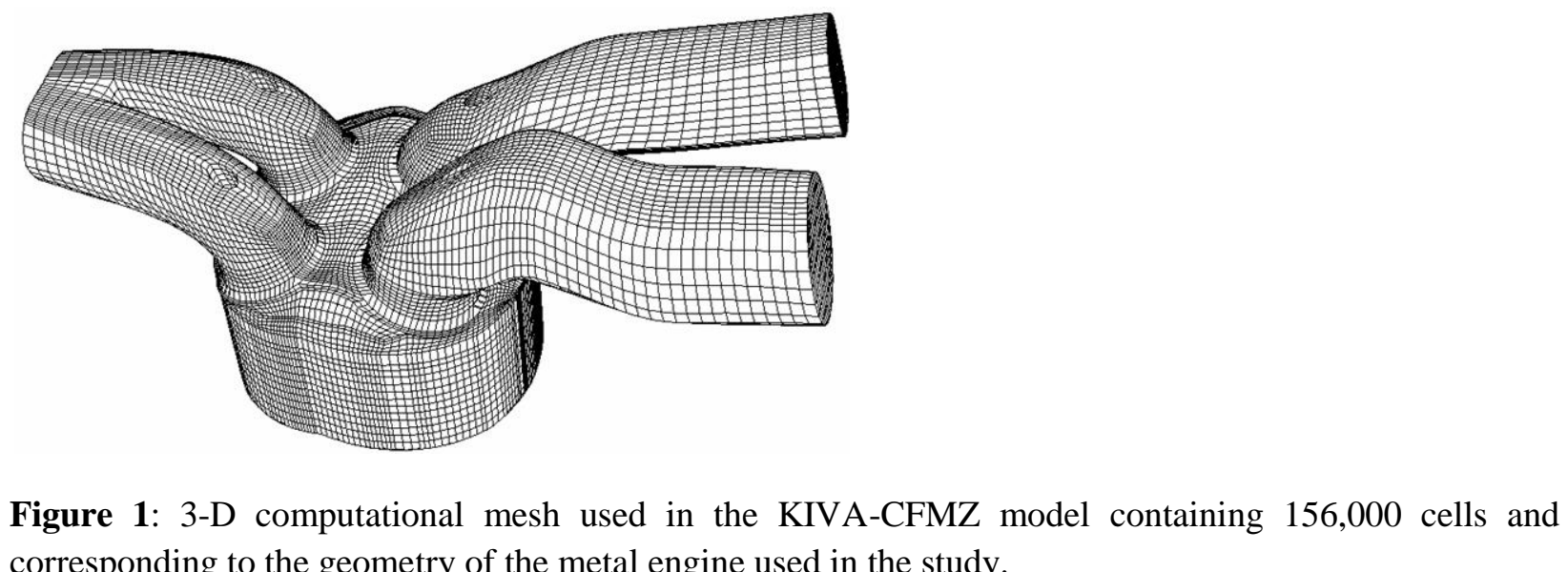

Figures
Figure 1: 3-D computational mesh used in the KIVA-CFMZ model containing 156,000 cells and
corresponding to the geometry of the metal engine used in the study.

Figures
Figure 1: 3-D computational mesh used in the KIVA-CFMZ model containing 156,000 cells and
corresponding to the geometry of the metal engine used in the study.

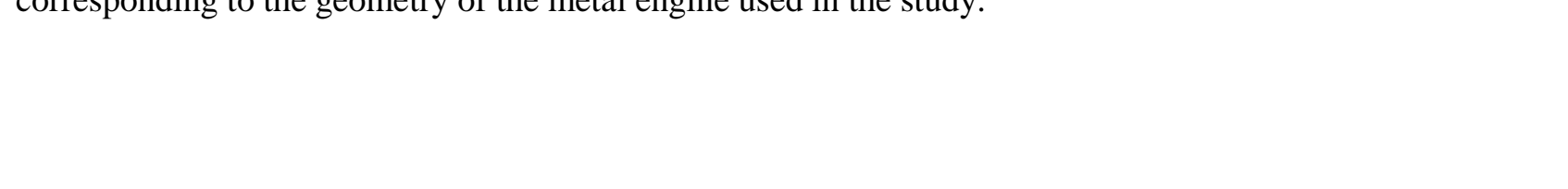

. coling

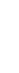

.

(1)
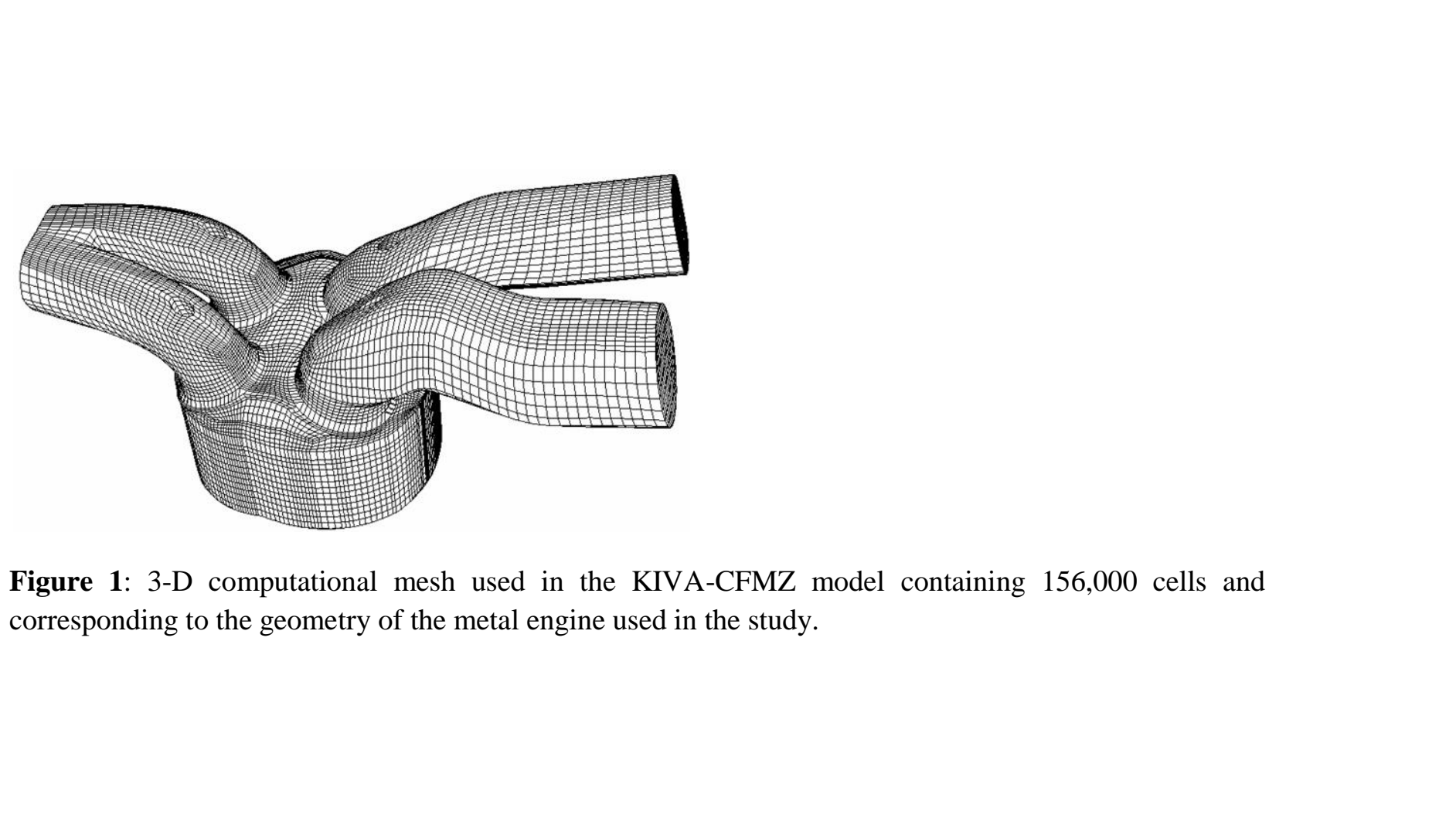

.

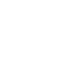



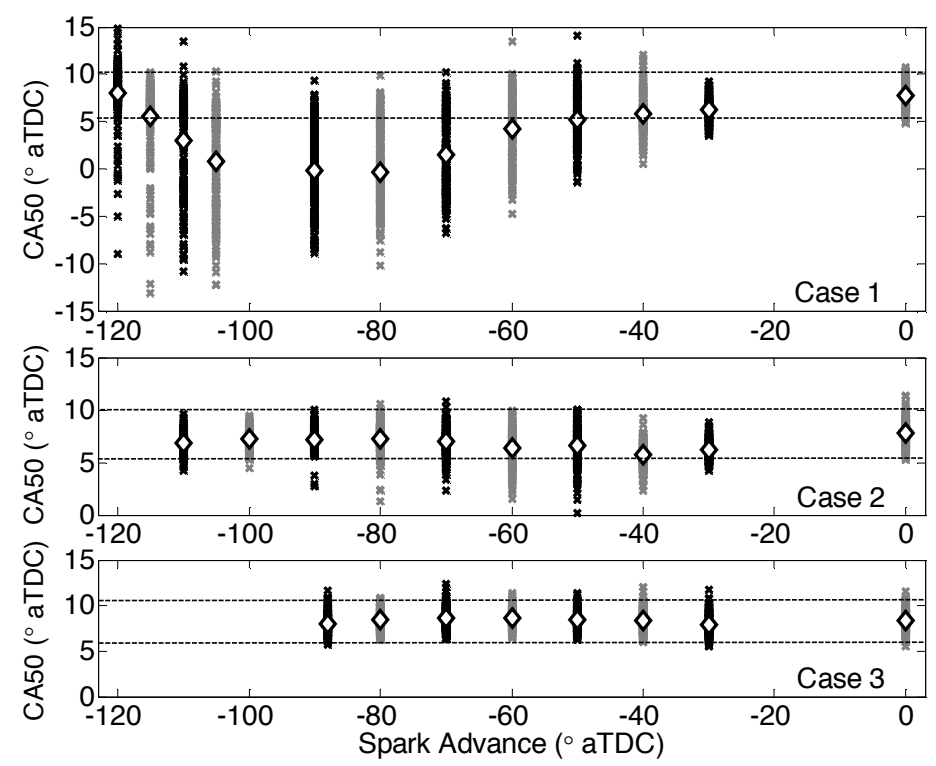

Figure 2: Response of CA50 to spark advance for the three Cases listed in Table 3. Data at $0^{\circ}$ spark timing are for the baseline HCCI conditions where no spark was used. Each dataset contains 200 consecutive cycles of pressure data. The diamond-shaped symbols are mean CA50 values. The dashed lines are $\pm 2 \sigma$ in CA50 for the HCCI conditions. 

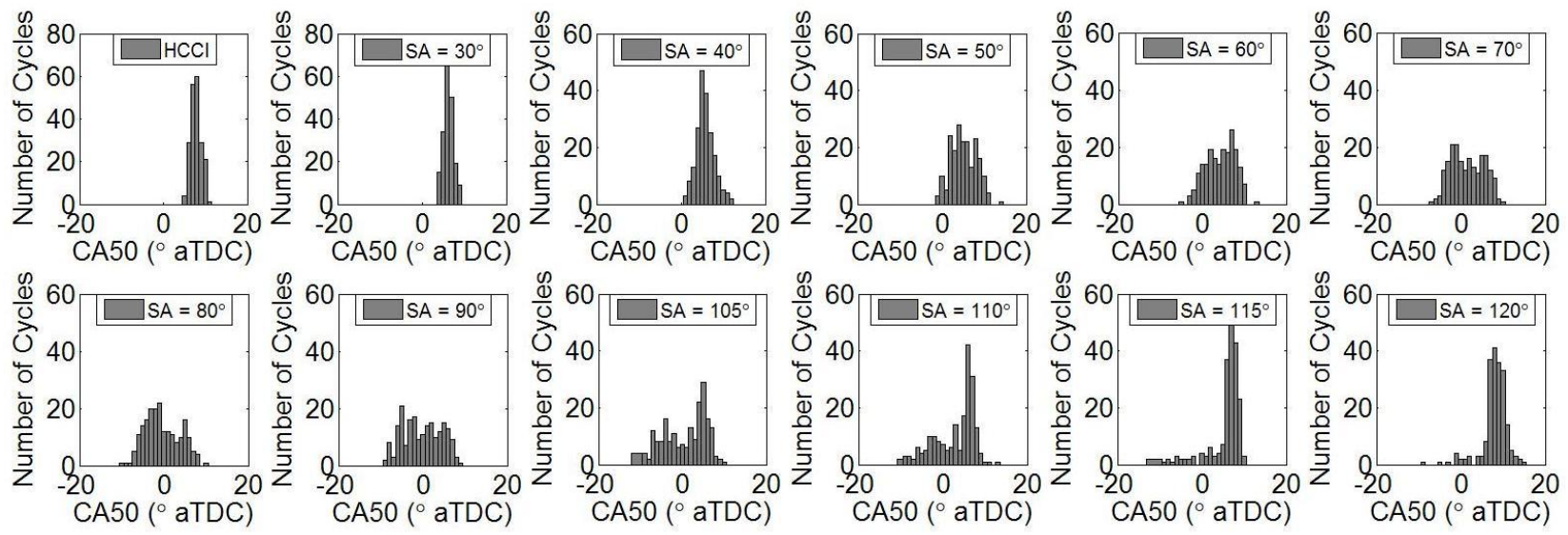

(a) Case 1
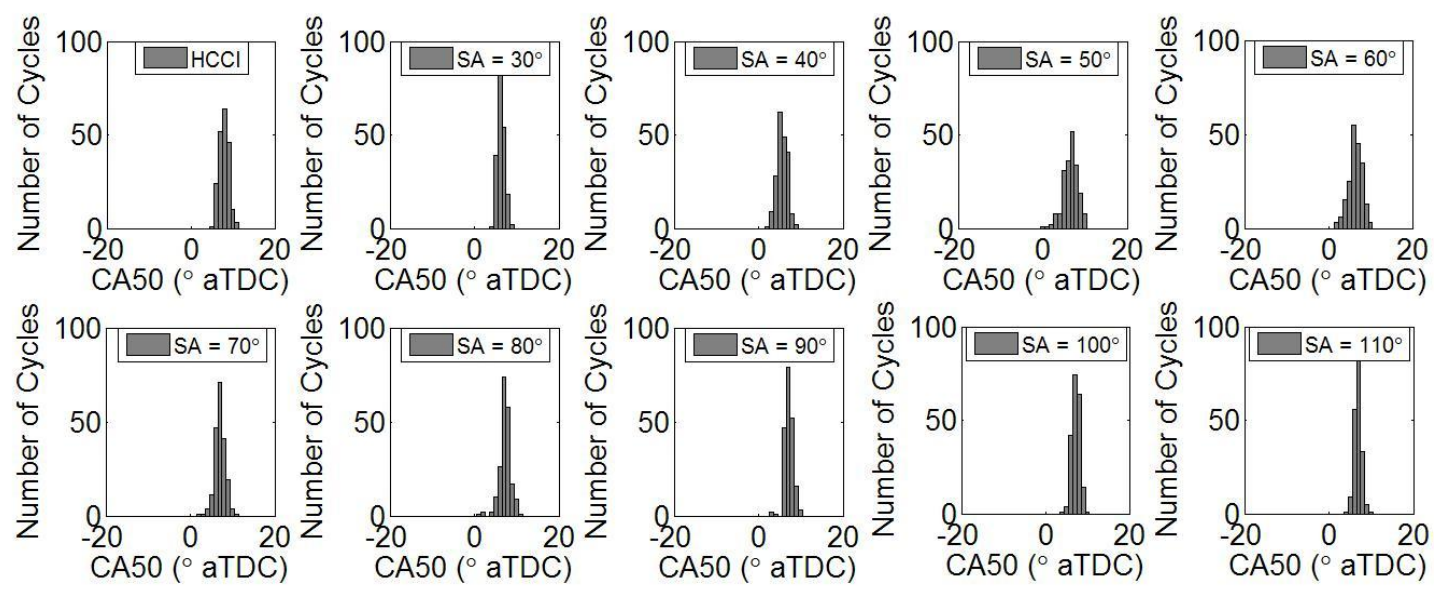

(b) Case 2
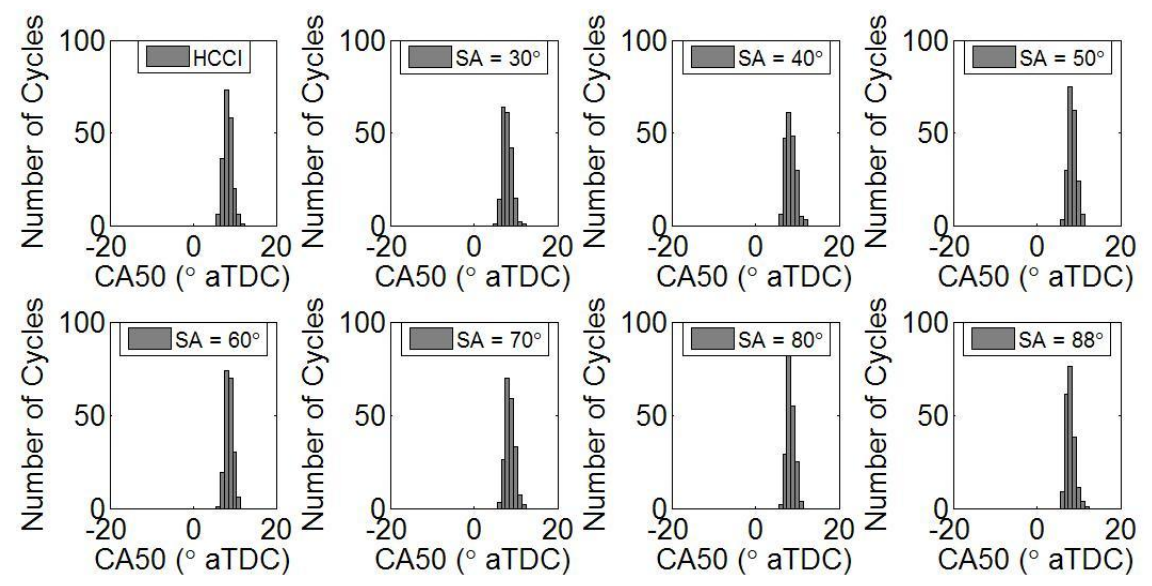

(c) Case 3

Figure 3: Histograms of CA50 containing 200 consecutive cycles for each condition presented in Figure 2 - (a) Case 1, (b) Case 2, and (c) Case 3. Spark advance (SA) values are presented in crank angle degrees before TDC. 


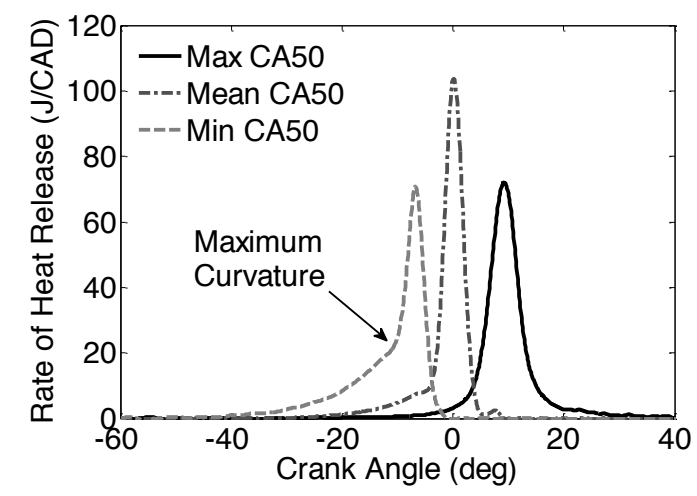

Figure 4: Heat release profiles of three individual cycles for Case 1 at a spark advance of $90^{\circ} \mathrm{bTDC}$. Each curve represents an individual cycle (out of 200): the most advanced cycle (minimum CA50), the most retarded cycle (maximum CA50), and the cycle whose CA50 falls closest to the mean value. Note that the most retarded cycle resembles HCCI combustion. 

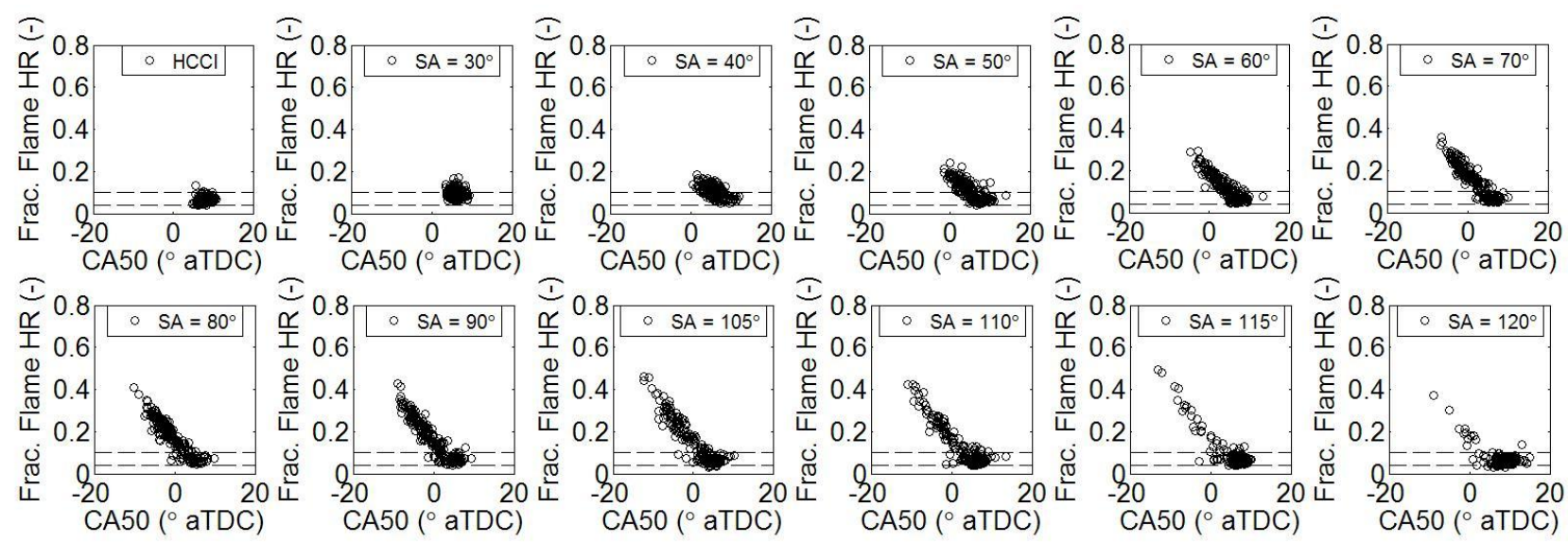

Figure 5: Estimated fraction of flame-based heat release (HR) as a function of CA50 for each cycle of the Case 1 conditions shown in Figure $3 \mathrm{a}$. The dashed lines represent the range of values determined from the baseline HCCI condition ( 4-10\%). The cycles with flame-based heat release above this range are advanced due to spark-induced flame propagation. 


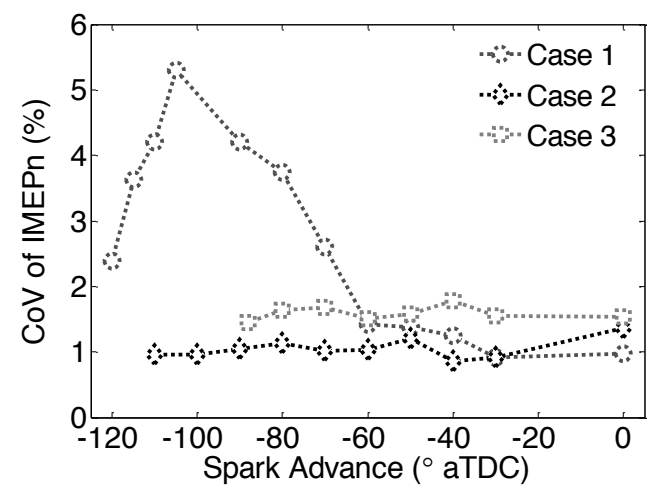

(a)

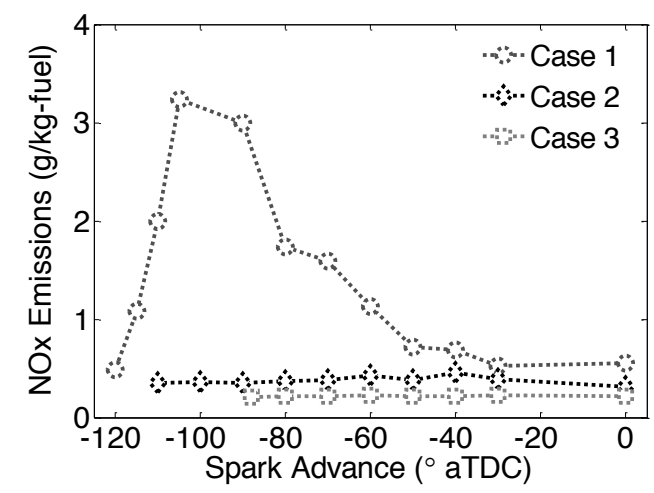

(b)

Figure 6: (a) CoV of $\mathrm{IMEP}_{\mathrm{n}}$ and (b) engine-out $\mathrm{NO}_{\mathrm{x}}$ emissions as a function of spark advance for each condition shown in Figure 2. Data at $0^{\circ}$ spark advance are for the baseline HCCI conditions. 


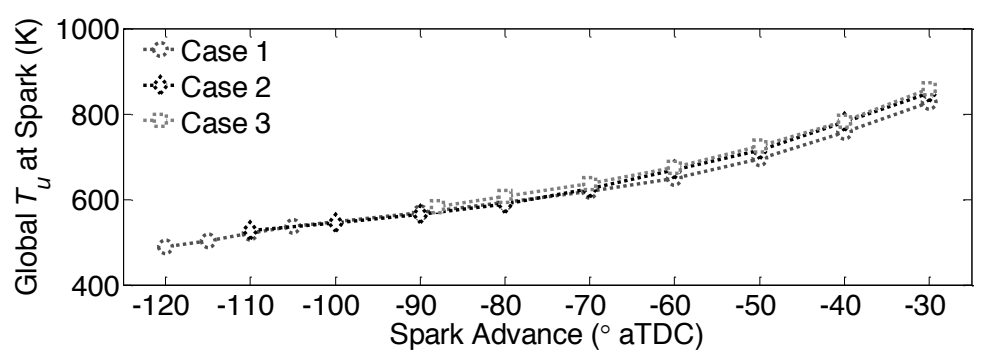

(a)

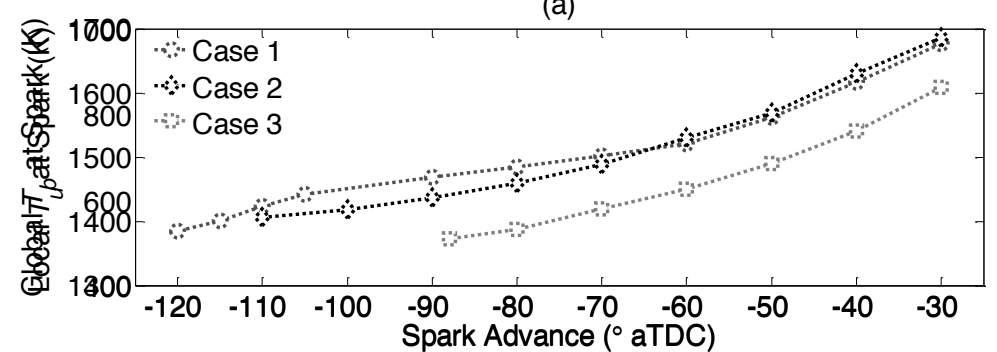

(a)

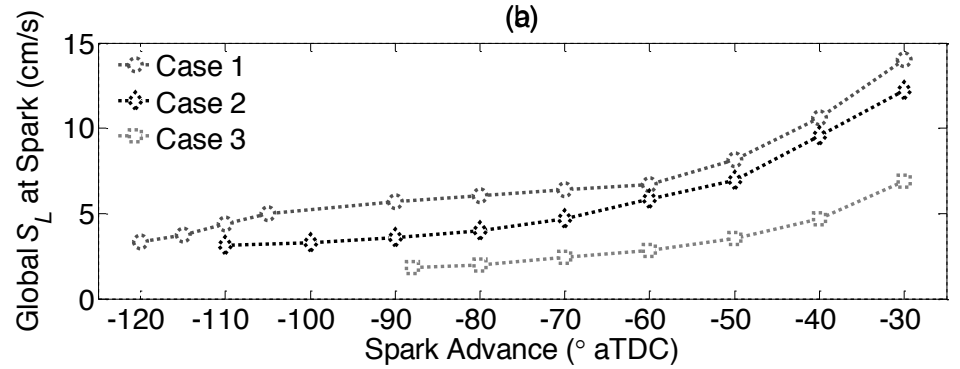

(c)

Figure 7: (a) Estimated mean global values of unburned gas temperature $\left(T_{u}\right)$ at the time of spark from heat release analysis; estimated values of (b) burned gas temperature $\left(T_{b}\right)$ and (c) laminar flame speed $\left(S_{L}\right)$ determined from the mean global state at the time of spark using the correlation of Middleton et al. [13]. 


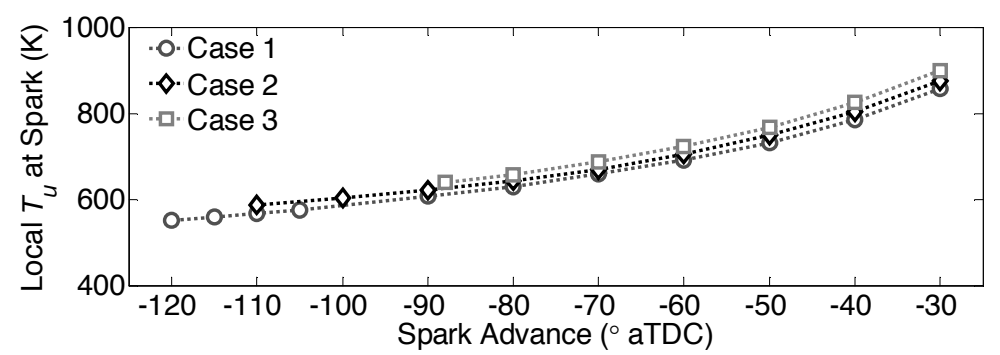

(a)

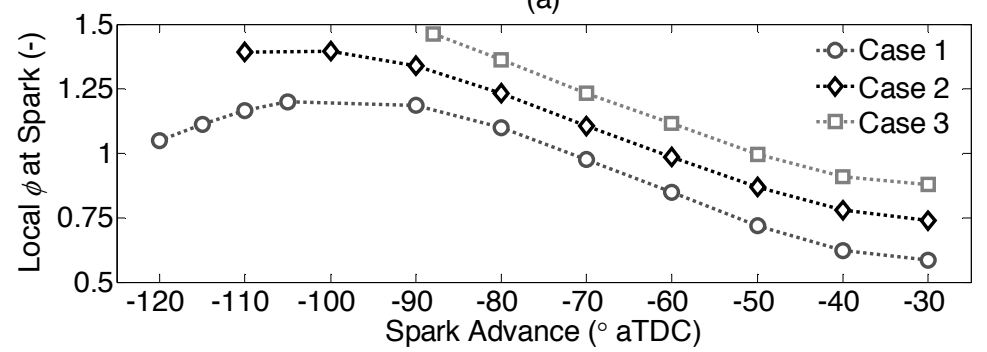

(b)

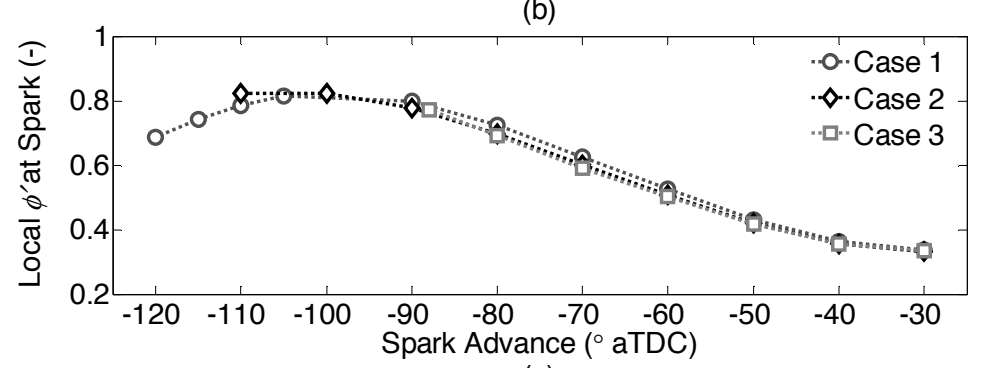

(c)

Figure 8: Estimated local values of (a) unburned gas temperature $\left(T_{u}\right)$, (b) fuel-to-air equivalence ratio $(\phi)$, and (c) fuel-to-charge equivalence ratio $\left(\phi^{\prime}\right)$ at the time of spark determined from the KIVA-3V engine model [34] within a $1 \mathrm{~cm}^{3}$ volume around the spark plug. 

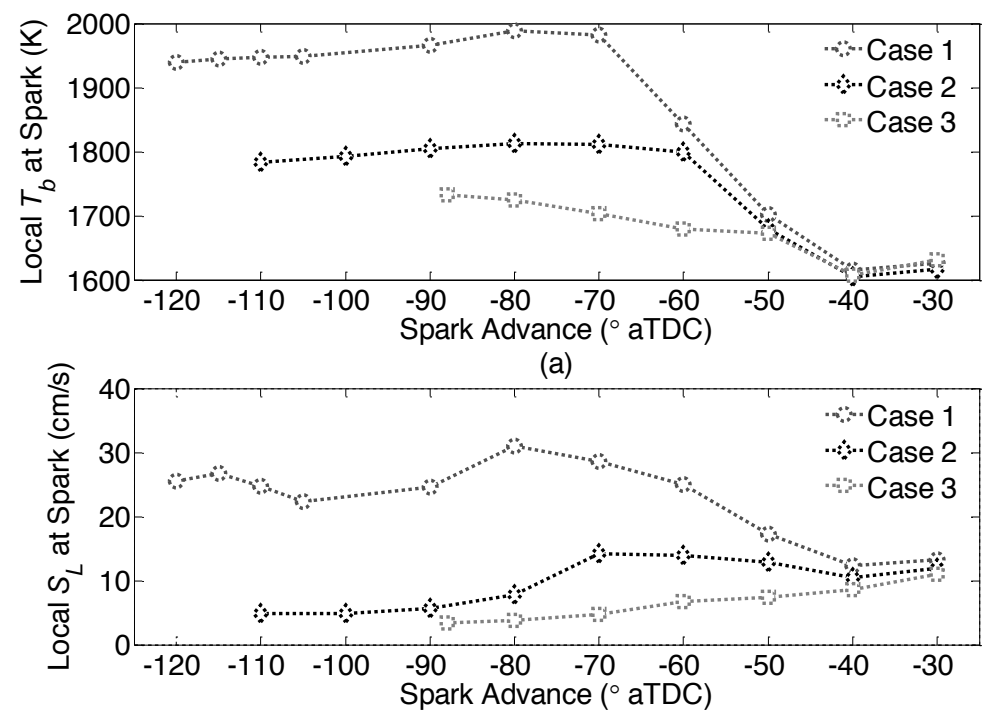

(b)

Figure 9: Estimated values of (a) burned gas temperature $\left(T_{b}\right)$ and (b) laminar flame speed $\left(S_{L}\right)$ determined from the local state at the time of spark using the laminar flame speed correlation of Middleton et al. [13]. 


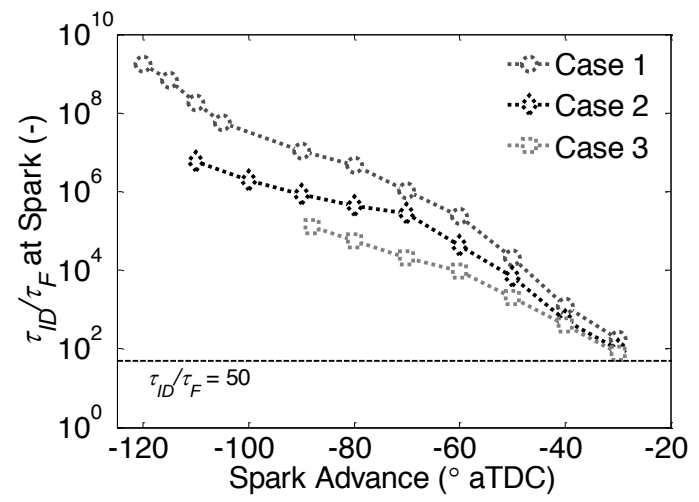

(a)

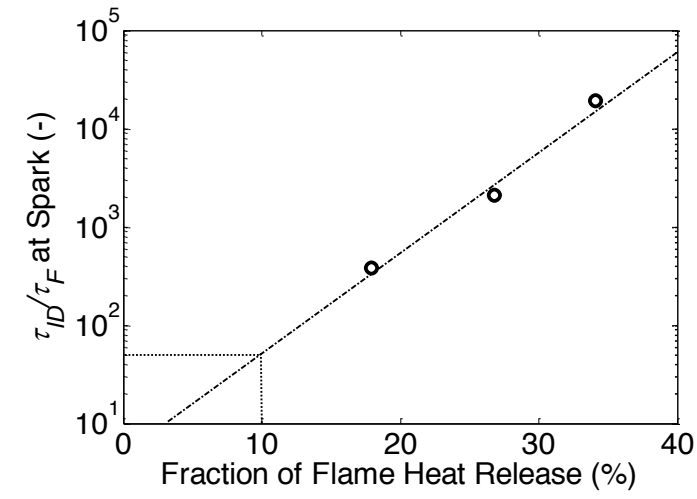

(b)

Figure 10: (a) Ratio of ignition delay time $\left(\tau_{I D}\right)$ to flame time $\left(\tau_{F}\right)$ calculated at the time of spark for each condition. Note that the y-axis is a logarithmic scale. (b) $\tau_{I D} / \tau_{F}$ plotted against the mean fraction of flame-based heat release for SACI data presented in Olesky et al. [43]. Extrapolating the trend line to flame-based heat release fractions of $10 \%$ yields a value for $\tau_{I D} / \tau_{F}$ of $\sim 50$, which is the value where heat release due to the flame is projected to be indistinguishable from the intermediate temperature heat release of the end-gas. 


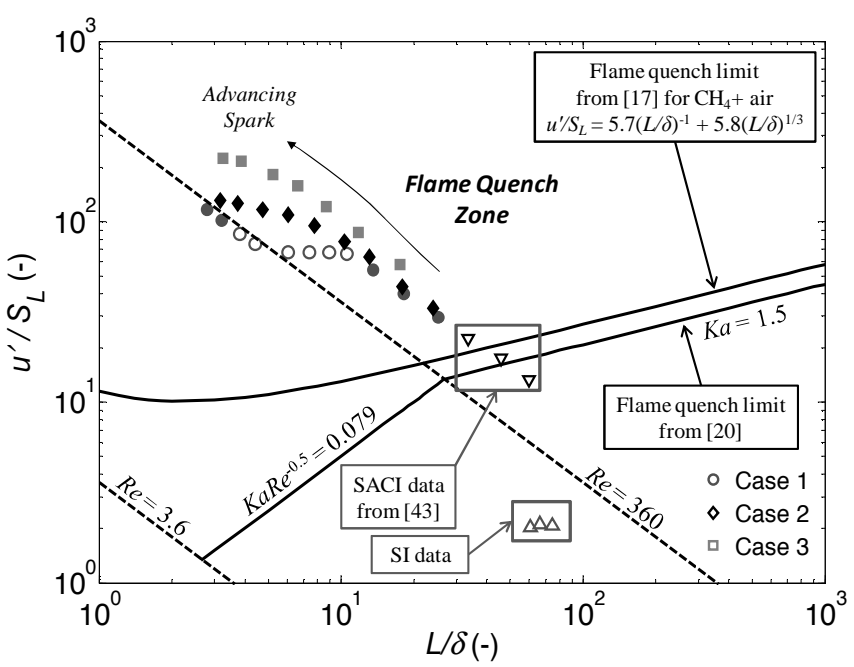

(a) Global

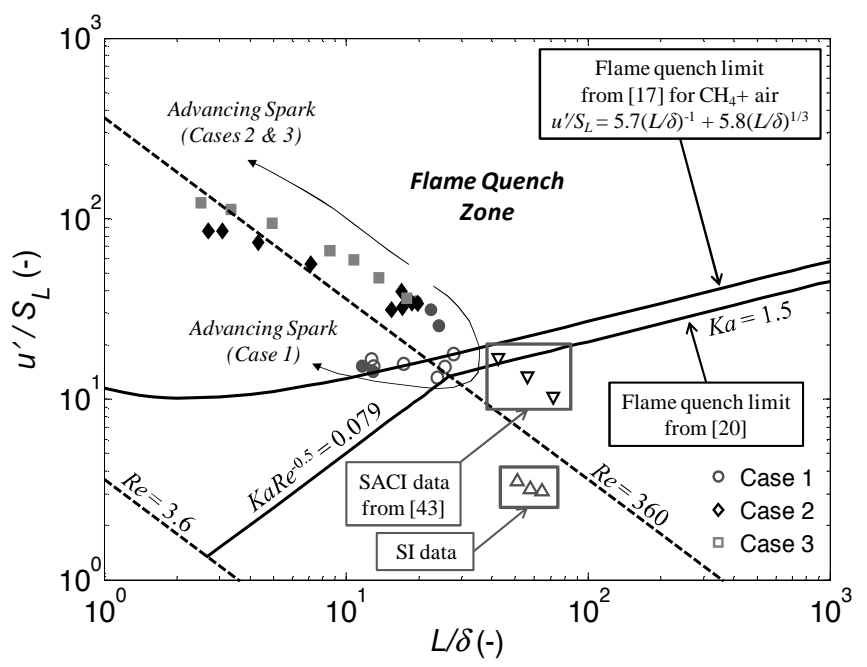

(b) Local

Figure 11: Leeds diagram showing estimates of the flame characteristics using (a) the global state at the time of spark and (b) the local state in the vicinity of the spark plug determined from KIVA-3V [34] at the time of spark. Flame quenching was defined to occur for the conditions in which the mean CA50 was within $\pm 2 \sigma$ of the CA50 distribution for the baseline HCCI Cases. These conditions are represented by closed markers and non-quenching conditions are represented by open markers. 